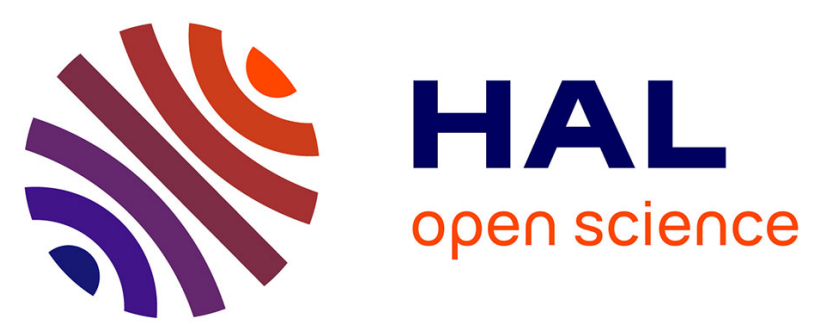

\title{
Avian uterine fluid proteome: exosomes and biological processes potentially involved in sperm survival
}

Cindy Riou, Aurélien Brionne, Luiz-Augusto Cordeiro, Grégoire Harichaux, Audrey Gargaros-Ratajczak, Valérie Labas, Joël Gautron, Nadine Gérard

\section{To cite this version:}

Cindy Riou, Aurélien Brionne, Luiz-Augusto Cordeiro, Grégoire Harichaux, Audrey GargarosRatajczak, et al.. Avian uterine fluid proteome: exosomes and biological processes potentially involved in sperm survival. Molecular Reproduction and Development, 2020, acceptée (4), Acceptée. 10.1002/mrd.23333 . hal-01605894

\section{HAL Id: hal-01605894 https://hal.science/hal-01605894}

Submitted on 26 May 2020

HAL is a multi-disciplinary open access archive for the deposit and dissemination of scientific research documents, whether they are published or not. The documents may come from teaching and research institutions in France or abroad, or from public or private research centers.
L'archive ouverte pluridisciplinaire HAL, est destinée au dépôt et à la diffusion de documents scientifiques de niveau recherche, publiés ou non, émanant des établissements d'enseignement et de recherche français ou étrangers, des laboratoires publics ou privés. 
Avian uterine fluid proteome: exosomes and biological processes potentially involved in sperm survival
Riou Cindy ${ }^{1,2}$, Brionne Aurélien ${ }^{3}$, Cordeiro Luiz ${ }^{1,4}$, Harichaux Grégoire ${ }^{5}$, Gargaros Audrey ${ }^{5}$, Labas Valérie ${ }^{5}$, Gautron Joël ${ }^{3}$, Gérard Nadine ${ }^{1,6}$

${ }^{1}$ PRC, INRA, CNRS, IFCE, Université de Tours, 37380, Nouzilly, France

${ }^{2}$ ALLICE, Station de Phénotypage, Lieu-Dit Le Perroi, 37380 Nouzilly, France

${ }^{3}$ BOA, INRA, Université de Tours, 37380, Nouzilly, France

${ }^{4}$ Federal University of Semi Arid Region, Mossoro, 59625-900, Rio Grande do Norte, Brazil

${ }^{5}$ INRA, Université de Tours, CHU de Tours, Plate-forme de Chirurgie et Imagerie pour la Recherche et l'Enseignement (CIRE), Pôle d'Analyse et d'Imagerie des Biomolécules (PAIB), F-37380 Nouzilly, France

${ }^{6}$ Corresponding author. Email: nadine.gerard@inra.fr

Keywords: uterine fluid, sperm, exosomes, avian, proteome

7 Grant Sponsor: Conseil régional du Centre Val de Loire, grant name : OVISPERM. 
Uterine fluid is an aqueous milieu to which sperm are exposed during their storage and ascent. In this study a bottom up proteomic strategy and bioinformatic analysis of hen uterine fluid was performed to improve understanding of this fluid and its potential role in sperm survival mechanisms. The proteomic data were submitted to ProteomeXchange. Among the 913 proteins identified, 160 are known to be secreted and 640 are referenced in exosomes databases. We isolated exosomes from avian uterine fluid, analyzed them using electron microscopy and targeted several exosomes markers (ANXA1/2/4/5, VCP, HSP90A, HSPA8, PARK7, and MDH1) using immunoblotting. Electron microscopy and immunohistochemistry were also used to analyze uterovaginal junctions for the exosomal proteins ANXA4, VCP and PARK7. Exosomes were observed both at the surface epithelium and inside sperm storage tubules. Our data were compared to two previously published studies on proteomic of hen uterine fluid, and with one study describing the proteomic content of rooster seminal plasma and sperm. In conclusion, we demonstrated for the first time that avian uterine fluid contains exosomes. These may play a key role in preserving sperm functions within the female genital tract. Their presence in the sperm storage tubules may represent an important mechanism regarding interaction between the female genital tract and sperm. 


\section{Introduction}

Avian species have the capacity to store sperm for several weeks in the female genital tract (Bakst et al., 1994; Birkhead \& Moller, 1993). Sperm reservoirs, mainly located in the mucosa of the utero-vaginal junction (UVJ), are called sperm storage tubules (SST) (Bakst, 2011).

The female avian reproductive tract (oviduct) consists of the infundibulum, magnum, white isthmus, uterus and vagina, which are associated with the egg components. The infundibulum ensures the deposition of the vitelline membrane outer layer. The developing egg then enters the magnum, where the egg white is produced ( 0.5 to 3.5 hours post ovulation). In the isthmus, eggshell membranes are synthesized ( 3.5 to 5 hours post ovulation). Then eggshell calcification takes place in the uterus within an 18 hours period. At that time, the egg mass in the uterus compresses the UVJ folds that are positioned towards the uterus, resulting in its mucosa being contiguous with those of the uterine tissue (Bakst \& Akuffo, 2009), as shown schematically in Figure 1. Finally, 24 hours after ovulation, the egg transits through the vagina and is laid. After mating, at the same time as the daily process of egg formation, sperm pass through the vagina and are stored in the uterovaginal SST (UVJ-SST) for several days. Then, the sperm transit from the UVJ-SST to the infundibulum, which is the site of fertilization (Sasanami et al., 2013).

Uterine fluid (UF) is the only reproductive fluid described yet in the avian reproductive tract. It represents the aqueous environment in which sperm is exposed during its ascent from the vagina to the infundibulum. Uterine fluid has been widely investigated over the past few years in relation to the egg formation (Gautron et al., 2019). It is a selective transudate of serum which also contains locally produced factors, mainly related to the metabolic activity of uterine epithelial cells. It contains several key proteins involved in the eggshell mineralization process that occurs from 5 hours after ovulation (Marie et al., 2015; Sun et al., 2013). It is also composed of bactericidal factors, providing an aseptic package for embryo development (Gautron et al., 2019; Gautron et al., 2007; Silphaduang et al., 2006; Wellman-Labadie et al., 2008).

Additionally to the fact that the secretory activity of the reproductive tract depends to the egg formation, UF has been shown to promote the maintenance of sperm motility and viability (Ahammad et al., 2013; Brillard et al., 1987). Actually, Ahammad et al. (2013) demonstrated that the stage of the secretory activity of the female reproductive tract has an incidence on the sperm storage efficiency. They showed that the filling of UVJ-SST is more effective when insemination is performed during initialization of eggshell mineralization (i.e. 5-6 hours after ovulation) than the calcifying phase (Ahammad et al., 2013). Thus, sperm may be more efficiently stored when inseminated at the beginning of the eggshell formation, when the secretory activity of the uterus increases and the UF is highly secreted. Under these conditions hens exhibit a longer period of fertile egg production (Brillard et al., 1987). Consequently, it has been postulated that UF constituents are essential for sperm storage efficiency in birds. Furthermore, we can hypothesize that some key proteins localized at the surface epithelium or in the lumen of the SST may originate from other regions of the genital tract such as by UF. Then these may adhere to the epithelium in order to enhance sperm retention within SST, preserve sperm function and/or regulate their release. Nevertheless, the mechanisms involved are still poorly understood. 
77 Many biological fluids have been shown to vehicle molecules not only as soluble/secreted 78 forms, but also engulfed in cell-derived membranous extracellular vesicles (EV). These are 79 involved in the transfer of molecules from one cell to another, and thus play an important role 80 in cell-to-cell signaling (Valadi et al., 2007). To date, in mammals, only a few studies have 81 described the presence of EV in the fluid from of the female genital tract. In birds, Baskt and 82 Bauchan (2015) demonstrated the presence of 30-130 nm EV in the lumen of turkey UVJ-SST 83 (Bakst \& Bauchan, 2015), and more recently Huang et al (2017) showed that SST cells produce 84 exosomes in vitro in the presence of sperm (Huang et al., 2017). In this study, we hypothesized that UF contained molecules that may preserve sperm during their storage and ascent in the female genital tract. We aimed to determine the protein composition of UF using proteomic analysis, to examine its EV content, and thus understand better the potential underlying mechanisms involved in the sustained sperm survival. We demonstrated that avian UF contained EV, particularly exosomes, which may play a role in the preservation of sperm functions during storage and ascent. Their presence in the SST may represent a mechanism of genital tract-sperm interaction involved in sperm survival. 


\section{Birds}

Mature female domestic hens from a light broiler-type strain (Beaumont et al., 1992) were used in this study. Breeding procedures and handling protocols were carried out in accordance with the European Union Council Directives regarding practices of animal care and use, practices of the French Ministry of Agriculture on animal experimentation, under the supervision of an authorized scientist (Authorization \# 37035). The facilities at the Institut National de la Recherche Agronomique, UE-PEAT 1295, are officially authorized to rear and euthanize birds (B27-175-1 dated 28/08/2012). At 50 weeks of age, hens were placed in individual cages equipped with automatic devices to record the time of oviposition. They were kept under a 16L: 8D photoperiod, and fed a layer mash ad libitum. The protocol of bird management and collection was approved by the local ethics committee (Comité d'éthique de Val de Loire ${ }^{\circ}{ }^{19}$ ) and the French Ministry of Research under agreement number \# 443.

\section{Uterine fluid collection}

UF collection was scheduled $10 \mathrm{~h}$ after oviposition and after confirming the presence of an egg in utero. Egg expulsion was induced by intravenous injection of prostaglandin F2A at $50 \mu \mathrm{g} / \mathrm{hen}$. During egg expulsion UF was collected in a plastic tube placed at the entrance of the everted vagina, from 10 virgin hens as described previously (Gautron et al., 1997). An aliquot of each UF was immediately diluted with 5x Laemmli buffer (5v:1v) (312.5 mM Tris-HCl pH 6.8, 10 $\%$ SDS, $12.5 \% \beta$-mercaptoethanol, $50 \%$ glycerol, bromophenol blue), and then boiled for 5 min before storage at $-20^{\circ} \mathrm{C}$. Two other aliquots of fluid per hen were diluted with PBS $(1 \mathrm{v}: 1 \mathrm{v})$ to limit calcium carbonate and proteins precipitation, in order to perform in solution digestion MS analysis, and to measure protein concentration.

\section{Tissue Collection}

Avian UVJ were collected from 6 hens for immunohistochemistry and transmission electron microcopy. Hens were euthanized by cervical dislocation. The genital tract section from uterus to vagina was excised as one segment. Connective tissue was removed to expose the uterovaginal junction. Samples of UVJ mucosa containing the UVJ-SST were collected from each hen and processed.

\section{SDS-PAGE with fractionation}

The protein concentrations of samples were determined using a Pierce ${ }^{\mathrm{TM}} \mathrm{BCA}$ protein assay kit, Thermofisher ${ }^{\mathrm{TM}}$. For exhaustive identification, the aliquots of UF collected from 10 females and diluted in Laemmli buffer (see above) were pooled by mixing the same amount of proteins from individual samples. Fifty $\mu \mathrm{g}$ of proteins from the pool of UF were fractionated by SDSPAGE (10\%) and stained with Coomassie Blue staining (PageBlue ${ }^{\text {TM }}$ Protein Staining Solution, Fermentas $\left.{ }^{\circledR}\right)$. Each lane was sectioned into 30 slices, which was cut into approximately $1 \mathrm{~mm} 3$ pieces. 
For liquid digestion $5 \mu \mathrm{g}$ of UF sample was pooled by mixing the same amount of proteins from individual samples collected from 10 females. For in-gel digestion each gel slice was washed in water/ACN (1:1) for $5 \mathrm{~min}$ and in $\mathrm{ACN}$ for $10 \mathrm{~min}$. For both digestions, cystein reduction and alkylation were performed by successive incubations in $10 \mathrm{mM}$ dithiothreitol/50 mM $\mathrm{NH}_{4} \mathrm{HCO}_{3}$ for $30 \mathrm{~min}$ at $56^{\circ} \mathrm{C}$ and $55 \mathrm{mM}$ iodoacetamide $/ 50 \mathrm{mM} \mathrm{NH}_{4} \mathrm{HCO}_{3}$ for $20 \mathrm{~min}$ at room temperature in the dark. For in-gel digestion, gel slices were washed by incubation in $50 \mathrm{mM}$ $\mathrm{NH}_{4} \mathrm{HCO}_{3} / \mathrm{ACN}(1: 1)$ for $10 \mathrm{~min}$ and by incubation in $\mathrm{ACN}$ for $15 \mathrm{~min}$. Proteins were digested overnight in $25 \mathrm{mM} \mathrm{NH}_{4} \mathrm{HCO}_{3}$ with $12.5 \mathrm{ng} / \mu 1$ trypsin (Sequencing Grade, Roche, Paris). For liquid digestion, the resulting peptides solution was dried, reconstituted with $13 \mu \mathrm{L}$ of $0.1 \% \mathrm{FA}$, $2 \% \mathrm{ACN}$, and sonicated for $10 \mathrm{~min}$ before MS analysis. For in-gel digestion, the resulting peptides were extracted from gel by successive incubations in $0.1 \%$ FA/ACN (1:1) for $10 \mathrm{~min}$ and in ACN for $5 \mathrm{~min}$. The two extracts were pooled, dried, reconstituted with $13 \mu \mathrm{L}$ of $0.1 \%$ FA, $2 \% \mathrm{ACN}$, and sonicated for $10 \mathrm{~min}$ before MS analysis.

\section{NanoLC-MS/MS}

Peptide mixtures were analyzed by nanoflow liquid chromatography-tandem mass spectrometry (nanoLC-MS/MS). All experiments were performed on a LTQ Orbitrap Velos mass spectrometer (Thermo Fisher Scientific, Bremen, Germany) coupled to an Ultimate ${ }^{\circledR}$ 3000 RSLC Ultra High Pressure Liquid Chromatographer (Dionex, Amsterdam, The Netherlands) controlled by Chromeleon Software (version 6.8 SR11; Dionex, Amsterdam, The Netherlands). Five microliters of each sample were loaded on an LCPackings trap column (Acclaim PepMap $100 \mathrm{C}_{18}, 100 \mu \mathrm{m}$ inner diameter x $2 \mathrm{~cm}$ long, $3 \mu \mathrm{m}$ particles, $100 \AA$ pores). Mobile phases consisted of (A) $0.1 \%$ FA, $97.9 \%$ water, $2 \% \mathrm{ACN}(\mathrm{v} / \mathrm{v} / \mathrm{v}$ ) and (B) $0.1 \% \mathrm{FA}, 15.9$ $\%$ water, $84 \% \mathrm{ACN}(\mathrm{v} / \mathrm{v} / \mathrm{v})$. Peptides were desalted and preconcentrated for $10 \mathrm{~min}$ at $5 \mu \mathrm{L} / \mathrm{min}$ with $4 \%$ solvent $\mathrm{B}$. The peptide separation was conducted using a LCPackings nano-column (Acclaim PepMap $\mathrm{C}_{18}, 75 \mu \mathrm{m}$ inner diameter x $50 \mathrm{~cm}$ long, $3 \mu \mathrm{m}$ particles, $100 \AA$ pores). The gradient consisted of $4-55 \%$ B for $90 \mathrm{~min}, 55$ to $99 \%$ B for $1 \mathrm{~min}$, constant $99 \%$ B $20 \mathrm{~min}$ and return to $4 \% \mathrm{~B}$ in $1 \mathrm{~min}$. The column was re-equilibrated for $15 \mathrm{~min}$ at $4 \% \mathrm{~B}$ between runs. The nanoflow rate was set at $300 \mathrm{nl} / \mathrm{min}$. Data were acquired using Xcalibur software (version 2.1; Thermo Fisher Scientific, San Jose, CA). The instrument was operated in positive mode in datadependent mode. Resolution in the Orbitrap was set at $\mathrm{R}=60,000$. In the scan range of $\mathrm{m} / \mathrm{z}$ $300-1800$, the 20 most intense peptide ions with charge states $\geq 2$ were sequentially isolated (isolation width, $2 \mathrm{~m} / \mathrm{z} ; 1$ microscan) and fragmented using Collision Induced Dissociation (CID). The ion selection threshold was 500 counts for MS/MS, and the maximum ion accumulation times allowed were $500 \mathrm{~ms}$ for full scans and $25 \mathrm{~ms}$ for CID-MS/MS. Target ion quantity for FT full MS was $1 \mathrm{e} 6$ and for $\mathrm{MS}^{2}$ it was 1e4. The resulting fragment ions were scanned at the "normal scan rate" with $q=0.25$ activation and activation time of $10 \mathrm{~ms}$. Dynamic exclusion was activated for $30 \mathrm{~s}$ with a repeat count of 1 . The lock mass was enabled for accurate mass measurements.

\section{Protein identification and data validation}

Raw data files were converted to MSF with Proteome Discoverer software (version 1.4; Thermo Fischer Scientific, San Jose, USA). A precursor mass range of 350-5000 Da and signal to noise 
ratio of 1.5 were the criteria used for generation of peak lists. The MS proteomics data were converted using a PRIDE Converter (version 2.5.3) (Deutsch et al., 2017; Perez-Riverol et al., 2019) and deposited with the ProteomeXchange Consortium (http://proteomecentral.proteomexchange.org) via the PRIDE partner repository with the dataset identifier [submitted] and project [submitted]. The peptide and fragment masses obtained were matched automatically against the Chordata section of a locally maintained copy of nrNCBI (1601319 sequences). MS/MS ion searches were performed using MASCOT Daemon and search engine (version 2.3; Matrix Science, London, UK). The parameters used for database searches included trypsin as a protease with two missed cleavages allowed, and carbamidomethylcysteine, oxidation of methionine and N-terminal protein acetylation as variable modifications. The tolerance of the ions was set at $5 \mathrm{ppm}$ for parent and $0.8 \mathrm{Da}$ for fragment ion matches. Mascot results were incorporated in Scaffold 4 software (version 4.3, Proteome Software, Portland, USA). Peptide identifications were accepted if they could be established at greater than $95.0 \%$ probability as specified by the Peptide Prophet algorithm. Peptides were considered distinct if they differed in sequence. Protein identifications were accepted if they could be established at greater than $95.0 \%$ probability as specified by the Protein Prophet algorithm and contained at least two identified peptides. A false discovery rate was calculated as $<1 \%$ at the peptide or protein level. The abundance of identified proteins was estimated by calculating the emPAI using Scaffold software. A phylogenic tree was constructed with Clustal Omega and similar Gallus gallus proteins were searched in nr databases using blast in order to clarify the scaffold groups.

\section{Statistical, data mining and bioinformatics analysis}

Proteomic data were extracted from Scaffold software and analyzed using $\mathrm{R}$ language (http:/cran.r-project.org) after elimination of keratin and trypsin, as they were contaminants or resulted from the digestion process, respectively. For each protein the identifier, symbol and description of the annotated gene were extracted from nr NCBI database. Overlapping and continuous peptides from the same sequence were concatenated to create a longer peptide (reconstituted peptide), in order to remove the peptidic redundancy and to generate a higher strength for the next step of analysis. Longer peptide sequences were blasted against nr NCBI database limited to Gallus gallus taxon, using the blastp program (BLAST+ suite) (Camacho et al., 2009). The alignment result of each peptide for each protein was expressed as a global score of similarity (SIsc) and identity (IDsc). Only a perfect match (IDsc $=100 \%$ ) with a Gallus gallus protein allowed removal of redundancy inside protein groups. Proteins which were not strictly identified in the Gallus gallus database were: a) considered as ortholougous to Gallus gallus proteins when the blastp result indicated the same protein description and name as the Chordata Scaffold result, and b) considered as unknown Gallus gallus proteins when the blastp result did not share any similar name or protein description. The resulting file constituted the non-redundant proteome presented in the present study. Only proteins that display SIsc higher than $91 \%$ (in terms of their blast results, including the size of peptides and the profile of the match, i.e. number of mismatches and gaps) were considered orthologous to the previously identified proteins. The SecretomeP 2.0 (Bendtsen et al., 2004) (http://www.cbs.dtu.dk/services/SecretomeP/), as well as the Signal P 4.1 (Petersen et al., 2011) 
(http://www.cbs.dtu.dk/services/SignalP) servers were used as a prediction method of the secretion pathway (signal peptide-dependent or independent or via exosomes) for each proteins obtained in the present study. Our data were then compared to an exosome database which we constituted by merging Exocarta (human, rat, mouse), UniprotKB (chicken) and KEGG (chicken) databases (personal data). Extraction of conserved and functional domains from protein sequences using BioMart allow to classify proteins by molecular function (http://www.ensembl.org/biomart/martview). According to their molecular function, to the GOterm annotation from Uniprot and Genecards (chicken and mammals), and to the literature, proteins were categorized in three main putative functions of interest as mineralization, immunity and sperm survival. The molecular function of total UF and exosomal proteins were compared using Fisher's exact test. Our identified peptides were also compared to published quantitative proteome lists from avian UF and eggshell (Marie et al., 2015; Sun et al., 2013) using BLAST+ suite, and from rooster's seminal plasma and sperm using protein ID.

\section{EV preparation}

EV were obtained by serial centrifugations as previously described (Thery et al., 2006). Briefly, UF were pooled ( $\mathrm{n}=2$ to 5 animals/replicate) and the volume was completed to $5 \mathrm{ml}$ with PBS before being centrifuged at $100 \mathrm{~g}$ for $15 \mathrm{~min}$, followed by $12,000 \mathrm{~g}$ for $15 \mathrm{~min}$ to remove cells and cell debris. Two successive ultracentrifugations at 100,000g for 90min (Beckman L8-M with SW41T1 rotor) provided an exosome pellet. The pellet was resuspended in $50 \mu 1$ of PBS and stored at $-20^{\circ} \mathrm{C}$ until analysis. An aliquot of each initial pool and ultracentrifugation supernatant were also kept at $-20^{\circ} \mathrm{C}$.

\section{Transmission electron microscopy analysis of EV and uterovaginal junction}

EV were analyzed as whole-mounted vesicles deposited on EM copper/carbon grids for 5min, and contrasted for $10 \mathrm{~s}$ in $1 \%$ uranyl acetate. Grids were examined with a Hitachi HT7700 electron microscope operated at $80 \mathrm{kV}$ (Elexience - France), and images were acquired with a charge-coupled device camera (AMT). Tissue samples from uterovaginal junctions were fixed with $4 \%$ glutaraldehyde in $0.1 \mathrm{M} \mathrm{Na}$ cacodylate buffer $\mathrm{pH} 7.2$, for $4 \mathrm{~h}$ at room temperature. Following fixation, samples were transferred to cacodylate $0.1 \mathrm{M}$ buffer containing osmic acid $2 \%$ for $2 \mathrm{~h}$ at $20^{\circ} \mathrm{C}$. Samples were then dehydrated in graded baths of ethanol (70 to $\left.100 \%\right)$ and embedded in epon resin. Polymerisation was performed at $60^{\circ} \mathrm{C}$ for $48 \mathrm{~h}$. Ultrathin sections of $70 \mathrm{~nm}$ were prepared with an Ultracut Leica ultramicrotome. Sections were counterstained using uranyl acetate and lead citrate and observed using a CM10 Philips TEM at 80Kv. Images were acquired using a Megaview III camera coupled with AnaySIS solf imaging system software.

\section{Western blotting of EV proteins}

The protein concentration was determined in each sample of UF and EV using the Pierce ${ }^{\circledR}$ BiCinchoninic Acid protein assay kit (Life Technologies SAS, Saint Aubin, France) using bovine serum albumin as the protein standard and according to the manufacturer's instructions. Aliquots of $10 \mu \mathrm{g}$ of proteins from the UF samples, ultra-centrifuged UF (EV-depleted) samples, and isolated-EV samples that were added with 5x Laemmli buffer $(5 \mathrm{v}: 1 \mathrm{v})$ and boiled at $95^{\circ} \mathrm{C}$ for 5 minutes were loaded and separated on a 10\% SDS-PAGE, before being transferred to 
nitrocellulose filters. The membranes were washed with TBS $(10 \mathrm{mM}$ Tris, $150 \mathrm{mM} \mathrm{NaCl}, \mathrm{pH}$ 7.4) containing $0.1 \%(\mathrm{v} / \mathrm{v})$ Tween-20 (TBS-T), incubated for 1 hour in the blocking solution $(5 \%(\mathrm{w} / \mathrm{v})$ non-fat dry milk in TBS-T), and then overnight in the blocking solution containing anti-VCP (1:1000; mouse monoclonal; ab11433, Abcam, Paris, France), anti-HSP90A (1:1000; rat monoclonal; ADI-SPA-840-D, Enzo life sciences, Villeurbanne, France), anti-HSPA8 (1:500; rabbit polyclonal; bs-5117R, Bioss, Interchim, Montluçon, France), anti-MDH1 (1:1000; rabbit polyclonal; CSB-PA013621ESR1HU, Cusabio, Clinisciences, Nanterre, France), anti-PARK7 (1:1000; rabbit polyclonal; NB300-270 Novus biologicals, Bio-Techne, Lille, France), anti-ANXA2 (1:1000; rabbit polyclonal; CSB-PA001840HA01HU, Cusabio, Clinisciences, Nanterre, France), anti-ANXA5 (1:1000; rabbit polyclonal; CSBPA06384A0Rb, Cusabio, Clinisciences, Nanterre, France), anti-ANXA1 (1:1000; rabbit polyclonal; sc-11387, Santa cruz biotechnology, Heidelberg, Germany), anti-ANXA4 (1:1000; rabbit polyclonal; CSB-PA001845ESR2HU, Cusabio, Clinisciences, Nanterre, France), antiBPIFB3/OCX36 (1/5000), or anti-OC17 (1/1000) both rabbit polyclonal kindly provided by J. Gautron. The membranes were then sequentially washed with TBS-T, incubated for 1 hour in the blocking solution, then for 1 hour with peroxidase-conjugated secondary antibody, i.e. goat anti-rabbit IgG (A6154, Sigma-Aldrich, Saint Quentin Fallavier, France) or goat anti-mouse IgG (A4416 Sigma-Aldrich) or goat anti-rat IgG (112-036-003 Jackson ImmunoResearch, Interchim), diluted 1/5000 in the blocking solution and finally washed with TBS-T. The peroxydase activity was detected with the ECL select ${ }^{\mathrm{TM}}$ Western Blotting Detection Reagent (GE Healthcare, Velizy-Villacoublay, France) and the signal was captured using the ImageMaster VDS-CL bio imaging system (Amersham Biosciences/GE Healthcare).

\section{Immunohistochemistry on uterovaginal tissue}

Following fixation for 24 hours in 4\% saline buffered (PBS) formalin, tissue samples (UVJ mucosa) were transferred to two successive baths of $70 \%$ ethanol $(2 \times 30 \mathrm{~min})$, and then moved to an automated tissue processor system (Leica TP1020 Semi-enclosed Benchtop Tissue Processor). The samples were then embedded in paraffin (Leica EG1150 Modular Tissue Embedding Center, Leica Microsystems Richmond, Inc., Richmond, IL). Four to six 7- $\mu$ m thick sections were collected in sequence onto slides treated with $0.01 \%$ poly-L-Lysine in water, airdried overnight, stored at room temperature for 12 hours and then incubated overnight at $60^{\circ} \mathrm{C}$. The staining procedures consisted in deparaffinization for $5 \mathrm{~min}$ in toluene, followed by progressive rehydration ( 2 min each of $100 \%, 95 \%, 80 \%$ and $70 \%$ ethanol bathes, ) and removal of excess ethanol by water baths. After rehydration, the slides were treated with $1 \%$ citrate based unmasking solution H3300 (Vector Laboratories, Burlingame, CA) diluted as recommended by the manufacturer. The slides were rinsed once in TBS for $5 \mathrm{~min}$ and then placed in a bath with normal horse serum blocking solution (Vector) for $20 \mathrm{~min}$. The slides were incubated overnight at $4^{\circ} \mathrm{C}$ with the primary antibodies, anti-VCP $(1: 500$; mouse monoclonal; ab11433, Abcam, Paris, France), anti-PARK7 (1:500; rabbit polyclonal; NB300270 Novus biologicals, Bio-Techne, Lille, France) or anti-ANXA4 (1:500; rabbit polyclonal; CSB-PA001845ESR2HU, Cusabio, Clinisciences, Nanterre, France) diluted in TBS with 5\% non-fat dry milk. The slides were then washed three times in TBS ( $5 \mathrm{~min})$, and incubated for 30 min with the secondary antibody ImmPRESS ${ }^{\text {TM }}$ HRP Anti-Rabbit/Mouse IgG (Vector). 
296 They were rinsed in TBS (5 min), incubated with peroxidase ImmPACT NovaRED (Vector)

297 and finally rinsed in distilled water $(5 \mathrm{~min})$. The sections were counterstained with

298 Papanicolaou stain (Sigma). Coverslips were applied with aqueous mounting medium after 299 dehydration through graded alcohol baths $(70 \%, 80 \% 95 \%, 100 \% ; 20$ s each) and the sections 300 were incubated in toluene for $1 \mathrm{~min}$. Sections were examined using an Axioplan Carl Zeiss 301 microscope. Images were acquired using a digital monochrome camera (Spot-Flex, Diagnostic 302 Instruments) coupled with the SPOT 5.2 imaging software. Negative controls for 303 immunohistochemistry were performed by the substitution of the primary antibody by an 304 isotypic-specific immunoglobulin at the same concentration. Figures are representative of 305 several observations performed on three hens per conditions. 
308

In the present study, a global proteomic inventory of soluble proteins present in the UF of lightbroiler-type hens was performed using GeLC-MS/MS followed by SDS-PAGE fractionation and then shotgun proteomic. After elimination of redundancies, a total of 913 UF proteins were identified (supplementary data 1). Their abundance within the sample was determined using the emPAI calculation. The two main components were Lysozyme and Albumin that displayed an emPAI value of 1000 and 999.99, respectively. Of the 913 proteins, 837 are already listed in the Gallus gallus database (supplementary data 1 part 1), 37 presented an orthologous protein (supplementary data 1 part 2), 39 corresponded to proteins not listed in the Gallus gallus database (supplementary data 1 part 3 ). A total of 875 proteins have already been identified in Aves species, compared to 38 proteins in Mammalia $(n=26)$, Reptilia $(n=7)$, Actinopterygii $(n=3)$, Amphibian $(n=1)$ or Cephalochordata $(n=1)$ (Figure $2 A)$. Of the 39 proteins not identified either in Gallus gallus or orthologous to Gallus gallus proteins, 18 have already been identified in Aves, whereas others were identified in Mammalia $(n=15)$, Reptilia $(n=3)$, Actinopterygii $(n=2)$, or Amphibian $(n=1)$ species. Among the 18 proteins identified in Aves species, some are related to the same family as Gallus gallus such as Meleagris gallopavo $(\mathrm{n}=7$ proteins), or to a neighboring order (Passeriformes, $n=9$; Psittaciformes, $n=1$; Falconiformes, $\mathrm{n}=1$ ). One of these 18 proteins displayed $90.7 \%$ similarity with ALDOA that was annotated in Falco peregrinus, whereas all the others displayed between $40.6 \%$ and $90 \%$ similarity with already sequenced avian proteins.

\section{Uterine fluid proteins which overlap with those from laying-type hens}

A few years ago, Sun et al., 2013 and Marie et al., 2015 revealed the UF protein composition for laying hens (White Leghorn and ISA-Hendrix, respectively) using a bottom-up proteomic approach (Marie et al., 2015; Sun et al., 2013). The proteome described in the current study and in these two previous studies were combined resulting in the identification of 1,230 avian UF proteins. Of to the 913 UF proteins described in the current study, we identified $153(16.8 \%)$ proteins common to the three studies (i.e. with a protein sequence similarity coefficient higher than 91\%) (Figure 2B). Their emPAI values ranged from 1,000 (rank 1) to 0.037 (rank 900). Moreover, 174 of our identified proteins were shared with one of the two previous studies. Out of these 327 shared proteins, 312 corresponded to a protein listed in the Gallus gallus database, 10 possessed a Gallus gallus orthologous protein and five corresponded to proteins that are not listed in the Gallus gallus database yet (supplementary data 1). None of the peptides from the remaining 586 proteins $(64.1 \%)$ revealed in our study had previously been identified in avian UF; they displayed emPAI values from 21.667 (rank 16) to 0.015 (rank 908).

\section{Analysis of uterine fluid proteins in relation to cellular localization}

Intracellular and extracellular localization of the 913 UF proteins identified in the present study are presented in Figure 3. The use of SecretomeP and SignalP bioinformatic tools demonstrated a total of $476 / 913$ proteins $(52.1 \%)$ that have already been categorized as secreted proteins. These either contained a signal peptide (155) or not (321). To date, the remaining 437 proteins (47.9\%) have not been referenced as potentially secreted proteins in either database (supplementary data 1). Of these 437 proteins, 324 (74.1\%) have previously been observed in 
biological fluids within EV named exosomes (UniprotKB, Exocarta and KEGG databases). Among the 913 UF proteins identified in the present study, 18 of the top 25 of the EV/exosome markers (Exocarta DB) have been found. Their emPAI values varied from 999.62 (rank 2) to 0.36 (rank 458). Moreover, we identified some proteins involved in multivesicular bodies (MVB) biogenesis such as Alix (PDCD6IP; emPAI=1.27; rank=162), TSG101 (emPAI=0.24; rank=578), and several proteins from the HSP70 family such as HSPA8 (emPAI=22.06; rank=17) and HSPA2 (emPAI=12.56; rank=24). Finally, to date only $113 / 913$ proteins $(12.4 \%)$ have not been categorized as secreted (Figure 3; supplementary data 1). These are mostly localized in cellular components such as cytosol, lysosomes, cytoskeleton and centrosome, when considering the GO-term enrichment in FunRich (human) or Genomatix (chicken) databases (data not shown). Their emPAI values ranged between 170.55 (rank 3) and 0.01 (rank 907). Out of these 113 proteins as yet not identified as secreted, 12 have already been identified in at least one of the two avian UF proteomics studies (Marie et al., 2015; Sun et al., 2013). Out of these, 108/113 proteins are listed in the Gallus gallus database, 2/113 have been identified in the Aves class and possess a Gallus gallus orthologous protein (ADPRHL1 and RPS6KA3) and 3/113 correspond to proteins that are not listed in the Gallus gallus database (Immunoglobulin A heavy chain variable region), but are already listed in the Aves class (Loc102114577 and MAPRE3).

\section{Analysis of EV/exosomes from UF and in SST}

The EV fraction purified from UF was analyzed using transmission electron microscopy (Figure $4 \mathrm{~A})$. It contained several vesicles of various sizes $(20.695-244.628 \mathrm{~nm})$. The majority ranged from 30 to $100 \mathrm{~nm}$ and was morphologically consistent with exosomes (Figure 4B). Immunodetection (Figure 4C) of exosomal and non-exosomal proteins demonstrated that VCP, HSP90A, HSPA8, ANXA2, MDH1, ANXA5, ANXA1, ANXA4 and PARK7 were present in the avian EV fraction, whereas BPIFB3 and OC-17 were not. Moreover, HSPA8, MDH1 and PARK7 signals were observed in EV-depleted UF.

TEM analysis of UVJ revealed the presence of exosomes $(30-100 \mathrm{~nm})$ at the surface of the epithelium (Figure 5A). Within SST, we observed intracellular MVB containing exosomes $(<100 \mathrm{~nm})$ (Figure 5B). We also detected apocrine blebs containing microvesicles (100-1000 $\mathrm{nm}$ ) (Figure 5C) in the lumen of SST.

\section{Immunohisto-localization of VCP, PARK7 and ANXA4 in SST}

SST are tubular glands localized in the UVJ whose role is to store sperm. Negative controls for immunohistochemistry demonstrated the absence of non-specific signals for all antibodies (Figure 6A). VCP, PARK7 and ANXA4, which are all known as exosome markers, were visualized within epithelial cells and lumen of SST (Figure 6B-D). A high ANXA4 signal was mainly observed on the apical part of the epithelium (Figure 6D).

\section{Analysis of uterine fluid proteins in relation to molecular functions}

The molecular functions of the 913 avian UF proteins identified in the present study were determined using InterPro, to extract the functional domains of each protein, followed by 
Uniprot description to attribute the molecular function. This showed a wide range of activities (Figure 7A). The major molecular function encompassed enzymes involved in various metabolic processes, such as glucose synthesis (MDH1, GPI, PGK, PKM, ALDOA, ENO1, etc.), lipid homeostasis (FASN, LYPLA1 and 2, PLA2G4A, PLCD1, etc.) and glutathione metabolism (GSTA3, GSTM2 and 3, GPX1 and 3, etc.). The UF also contained structural proteins mostly participating in cytoskeletal assembly (12 actin isoforms, 6 tubulin isoforms, GSN, etc.). Moreover, we observed the presence of a large number of chaperon proteins (HSP70 family HSPA2/ 4/ 4L and 8, DNAJA4/ B6/ B1/ B13 and C10, HYOU1, SGT1, STIP1, HSP90AA1, HSP90B1, subunits 2/ 3/ 4/ 5/ 6A/ 7 and 8 of T-complex protein 1, TCP1, PDIA3/ 4 and 6 , etc.). It is noteworthy that 29 and 27 proteins were associated with multivesicular body (MVB) biogenesis and membrane trafficking, respectively.

\section{Analysis of uterine fluid proteins in relation to biological processes}

Potential functions of the 913 proteins were examined with particular emphasis on eggshell mineralization, molecular defense against pathogens and sperm survival via exosomes.

The first functional group concerned mineralization (Table 1). It was composed of 59 proteins, of which 28 may be involved in the regulation of protein activity since they corresponded to proteases, phosphatases or chaperons related to mineralization. The other 31 proteins from this group possessed either calcium binding or proteoglycan/proteoglycans binding domains, or were included in collagen fiber (ECM components). They were major UF proteins that displayed emPAI between 1,000 (LYZ) and 0.03 (ROS1).

The second group concerned molecular defense (Table 2). It was made up of 48 proteins of which five contained microbial degrading components, five were involved in decreasing bioavailability of iron and vitamins, 27 displayed microbial protease inhibiting activity, 10 belonged to the immunoglobulin superfamily and one is known to mediate the immune response.

The third group contained proteins that potentially mediate sperm survival via the exosomes (Figure 7B). This exosome cluster was significantly $(\mathrm{p}<0.001)$ enriched with proteasomal proteins and comprises proteins involved in the ubiquitin pathway. It also contained chaperones or chaperone binding proteins including subunits from the TCP1-ring complex as well as HSPA8, HSPA2, HSP90AA1 and VCP. Moreover, it included antioxidant proteins comprising ALB, PRDX1, PRDX6, GSTA3, GSTO1, and GSTO1, and annexins. These latter include ANXA2, ANXA8, ANXA5 and ANXA1, which all possess phospholipase A2 inhibitor activity, and/or calcium binding properties.

\section{Uterine fluid proteins which overlap with avian semen proteins}

It is noteworthy that $396 / 913$ proteins that we described in avian UF have been identified in rooster seminal plasma $(143 ; 16 \%)$ or sperm $(99 ; 15 \%)$, or both $(154 ; 24 \%$, Labas et al., 2015). Furthermore, $330 / 396$ proteins belong to the exosome cluster, and to seminal plasma $(125 / 143$; $20 \%)$ or sperm $(64 / 99 ; 10 \%)$ or both $(141 / 154 ; 22 \%)$ (Figure 8$)$. 
The 125 proteins referenced in both exosomes and the seminal plasma were composed of 34 proteins involved in vesicle-mediated transport, 25 proteins involved in homeostasis, 24 proteins from metabolic pathways, five proteins possessing a serpin domain, eight proteins from complement and coagulation cascades and four proteins presenting antioxidant properties. The most abundant proteins from this group were LYZ, ACTB, PRDX6, GDI2, GC, GSTO1, ANXA8, ANXA5, AKR7A2 and SERPINF1.

The 64 proteins referenced in the exosomes and the sperm contained seven chaperones or chaperon binding proteins, nine proteins from proteasome or ubiquitin pathways, 19 proteins involved in metabolic process comprising six proteins from TCA cycle, and five proteins involved in fatty acid degradation. The most abundant proteins of this group included HSPA8 and TUBB4B.

The 141 proteins referenced in exosomes and in both the seminal plasma and the sperm were composed of 11 proteasomal proteins, 12 chaperons or chaperon binding proteins including eight subunits from the TCP1-ring complex, nine proteins exhibiting antioxidant properties, 31 proteins involved in metabolic pathways comprising 11 proteins taking part in glycolysis. The most abundant proteins were ALB, ACTG1, CKB, PRDX1, HBAA, ALDOC, ENO1, ANXA2, HSPA2, YWHAE, GAPDH and HSP90AA1.

Moreover, 66 non-exosomal proteins were identified in UF and either seminal plasma, sperm or both (Figure 8). Among them, the six main proteins were HBG2, UBC, Ig gamma chain (clone 36), PIT54, SPINK2 and immunoglobulin alpha heavy chain. 
447 In the present study, we performed an in-depth inventory of proteins present in avian UF using 448 classical proteomic approaches. We demonstrated for the first time that avian UF contains

449

450

451

452

453

454

455

456

457

458

459

460

461

462

463

464

465

466

467

468

469

470

471

472

473

474

475

476

477

478

479

480

481

482

483

484

extracellular vesicles, mainly exosomes. These EV represent a mechanism of oviduct-sperm interaction that may play an essential role in the preservation of sperm functions and sperm survival within the SST.

We compared our dataset, obtained with domestic hens from a light broiler-type strain ( $\mathrm{n}=913$ identified proteins) to those of Sun et al. (2013) and Marie et al. (2015) both relating to laying hens ( $\mathrm{n}=550$ and 308 protein sequences, respectively), revealing a list of 1,230 proteins of avian UF proteome. Our study allowed the number of proteins recently listed to be doubled (Marie et al., 2015).

\section{Proteins linked to shell formation that are potentially involved in sperm function}

Our study demonstrated that major proteins from the UF are involved in shell formation, as previously demonstrated (Marie et al., 2015). These proteins comprise eggshell matrix proteins unique to the process of shell formation such as ovocleidins (MEPE, also known as OC-116 and OC-17), ovocalyxins (LOC771972, RARRES1, and OCX36) and hydrolases, dehydratases, proteases, protease inhibitors, chaperones, proteins possessing calcium binding domains, and proteins involved in the composition of the extracellular matrix (proteoglycans, proteoglycans binding proteins, collagen modulating proteins; Table 1). All these are known to play a key role in shell formation (Gautron et al., 2007; Hincke et al., 2012; Nys et al., 2004). The UF collected during the initiation of mineralization (6-10 hours post oviposition) was shown to improve sperm motility in vitro (Ahammad et al., 2013; Brillard et al., 1987). Moreover, this stage was shown to be an optimal window for artificial insemination regarding the fertility of hens (Brillard et al., 1987). Therefore, it is reasonable to hypothesize that UF components involved in the constitution of shell organic matrix may be important for sperm survival and ascent through the uterus.

In mammals, ECM components like collagen and proteoglycan binding protein (FN1) may have an influence on the ability of sperm to stick to the extracellular matrix (Koehler et al., 1980). Our study revealed the presence of proteoglycans (MEPE, TSKU, GPC4, HSPG2) and proteins with abilities to bind proteoglycans (FN1, SDCBP, SERPINF1, HAPLN3, VTN, SERPIND1, SDCBP2), that may display antimicrobial functions. We also identified several proteins involved in the modulation of collagen fibers (PLOD1, PLOD2, MMP2, TNXB). Interestingly, knowing that MEPE is a protein core of dermatan sulfate proteoglycan, and that sulfated glycosaminoglycans are known to modulate sperm-oviduct binding and to trigger sperm release in mammals (Talevi \& Gualtieri, 2001), this protein may have a similar role in avian species. Moreover, it has been demonstrated recently that some proteoglycan binding proteins (FN1) interact with exosomes when in the presence of heparan sulfate glycosaminoglycan (Dismuke et al., 2016). These proteins, observed here in avian UF, could thus support the EV cargo and improve communication between the female genital tract and sperm. 
MEPE is assumed to be a calcium chelator (Hincke et al., 1999) and it thus could regulate calcium availability for sperm. This is in accordance with Froman's model which suggests that sperm motility is strongly linked to extracellular calcium (Froman, 2003). Moreover, in the present study we identified numerous calcium binding proteins (ALB, OVOT, ANXA2, OVAL, EDIL3, ANXA5, HPX, CALM, MFGE8 and GSN). A previous study (Fujihara \& Koga, 1984) demonstrated that calcium, used as an additive to sperm diluent, protects fowl sperm from deformation, lipid peroxidation and maintains fertility and motility in vitro. Albumin (ALB) exhibits antioxidant activity (Gum et al., 2004) and impacts fowl sperm motility in vitro (Blesbois \& Caffin, 1992), whereas MFGE8, localized on sperm plasma membrane, is considered as a key modulator of sperm-egg binding in vitro (Raymond et al., 2009). Our work also demonstrated the presence of CALR protein that has been described as a regulator of intracellular calcium of sperm during hyperactivation and acrosome reaction in mammals (Dun et al., 2012; Nakamura et al., 1993).

Other proteins involved in the remodeling of membrane events like PDIA3, HSP90B/B1 (Dun et al., 2012), or kazal domain proteins like SPINK5, SPINK7 and SPINK2 (Jalkanen et al., 2006; Lee et al., 2011; Slowinska et al., 2015) have been identified in avian UF. There, these proteins may participate, at least in part, to membrane changes leading to the functional modulation of sperm during storage and ascent before fertilization.

Carbonic anhydrase 2 (CA2) that has been described in the present study, has been previously hypothesized to be related to the modulation of $\mathrm{pH}$ in the lumen of SST in turkey, hens and quail (Holm \& Ridderstrale, 1998; Holm et al., 1996). It thus may be of major interest for sperm survival during its storage in the female genital tract by lowering of the $\mathrm{pH}$ in SST leading to the quiescence during storage.

Finally, UF proteins involved in eggshell mineralization could impact sperm features (plasma membrane, calcium levels), luminal features ( $\mathrm{pH}, \mathrm{EV}$ ), and interactions (cell-cell binding) and consequently regulate sperm survival and/or motility in the female genital tract.

\section{Proteins exhibiting antimicrobial activities potentially involved in sperm function}

We identified several antimicrobial proteins in the UF collected $10 \mathrm{~h}$ post oviposition. They are involved in the degradation of microbial components (LYZ, OC-17, BPIFCB, BPIFB3 and LOC102118097), in the decrease in iron and vitamin bioavailability (OVOT, GC, VTG2, AVD and VTG1), or in the inhibition of proteases (RARRES1, SPINKs, CST3, AMBP, OVALY, OVAX, SERPINs, OVSTL, C3, C5, A2M, LOC418892) (Réhault-Godbert et al., 2011). These antimicrobial proteins most probably act to maintain a bacteria-free environment for sperm during its storage and transit in the female genital tract, and participate to the sperm acceptance.

Among these proteins, several are known to regulate the shell mineralization process, such as calcium binding proteins (OVOT), ECM components (i.e. proteoglycan binding proteins) or others (LYZ, SPINKs, RARRES1, CST3, OC-17, SERPINs, OVSTL). SPINKs have been demonstrated to protect sperm from the proteolytic action of proteases from dead or damaged sperm in the epididymis, the testis, and the seminal plasma (Jalkanen et al., 2006; Lee et al., 2011; Slowinska et al., 2015). Therefore, the presence of SPINKs in the avian UF may 
contribute to the local proteases/proteases inhibitors homeostasis, regulate the proteolytic processing of the sperm surface proteins, and/or participate to sperm membrane changes during storage and ascent before fertilization.

Moreover, our study revealed several fragments of immunoglobulins. The immunoglobulin Ig gamma chain has recently been linked to sperm survival and has been proposed as a seminal marker of fertility in roosters (Labas et al., 2015). We also identified avidin in hen's UF, a protein which supports long term sperm storage in uterovaginal SST in turkey (Foye-Jackson et al., 2011; Long et al., 2003). Thus, both proteins may participate to the sustained sperm survival during storage in SST.

\section{Exosomal proteins potentially involved in sperm survival}

To our knowledge, our study is the first to demonstrate the presence of exosomes in avian UF collected 10 hours post-oviposition. Exosomes are extracellular vesicles released from cells that participate in several cellular processes and exhibit pleiotropic biological functions (Colombo et al., 2014). To date, they have been described in almost all body fluids, such as blood, urine, saliva and milk. In the female genital tract, exosomes have already been described and isolated from human and ovine uterine luminal fluid as well as from bovine oviductal fluid (Alminana et al., 2017; Burns et al., 2014; Ng et al., 2013). In avian species, they were observed in the lumen of UVJ-SST (Bakst \& Bauchan, 2015), and were demonstrated to be secreted in vitro by UVJ and vaginal cells (Huang et al., 2017). Therefore, one can hypothesize that exosomes from avian UF could provide an alternative mode of communication between epithelial cells of the genital tract and sperm cells during their ascent and storage in the female genital tract since exosomes are known to deliver ubiquitous and specific proteins, lipids, RNA and ions to recipient cells.

We isolated exosomes from avian UF and demonstrated that they contained HSPA8, HSP90A, VCP, annexins, PARK7 and MDH1. Moreover, in the UF we identified the antioxidant proteins PRDX1, PRDX6, GSTA3 and SOD1, the chaperones HSPA8, HSPA2 and HSP90AA1, and proteins involved in metabolic pathways like CKB, ALDOC, LDHB, GSTA3, GSTO1, GSTM3 and MDH1. All are known to be exosomal proteins as referenced in the Exocarta database.

Most of these components have already been shown to regulate sperm function, as reviewed in mammals (Dun et al., 2012; Yu \& Huang, 2015) and avian species (Breque et al., 2003; Hiyama et al., 2014).

Exosomes have been observed within SST, fusing with sperm plasma membrane, suggesting that they may sustain sperm storage in the SST (Bakst \& Bauchan, 2015). Moreover, we demonstrated that ANXA4, VCP and PARK7 were relevant markers of avian genital tract exosomes. ANXA4 was localized at the apical part of SST epithelial cells and VCP and PARK7 were localized intracellularly. Considering that in mammals annexins have been proposed as sperm receptors (Ignotz et al., 2007; Talevi \& Gualtieri, 2010), we can hypothesize that exosomes are key components for sperm survival during long term storage in the hen's genital tract. 
In the mammalian male, seminal plasma exosomes have been demonstrated to regulate fluidity of the sperm membrane (Piehl et al., 2013), and to ensure the transfer of key molecules involved in calcium signaling to sperm (Park et al., 2011). As a result of their fusogenic properties, exosomes from seminal plasma are capable of transferring molecules to sperm, thereby altering the sperm's cholesterol: phospholipid ratio, sperm function relative to their maturation, motility properties, and antioxidant capabilities (Sullivan et al., 2005). It has been proposed that exosomes may constitute a pool of enzymes/proteins used to replenish the enzymes/proteins which are insufficiently represented or have been lost from sperm (Ronquist et al., 2013). Similarly, we could hypothesize that exosome components may be transferred from UF exosomes to stored sperm to guarantee sperm membrane properties, motility, antioxidant capabilities, and fecundity before fertilization. Nevertheless, the impact of UF exosome components on sperm functions requires further investigation.

\section{Overlapping between avian $U F$ and semen proteins}

We compared our data to proteomic analysis of rooster's seminal plasma and sperm (Labas et al., 2015) in order to identify key proteins potentially involved in sperm survival. Several antioxidant proteins (ALB, PRDX1, SOD1, GPX3 and TXNL1) were common between UF, seminal plasma and sperm (Labas et al., 2015). SOD and GPX have been suggested to prevent peroxidation of sperm lipids in the hen's oviduct (Breque et al., 2003). Metabolic pathway proteins (CKB, ALDOC, ENO1, GAPDH, LDHB, GSTA3, MDH1, PGK1, TPI1, PKM, PGAM1, GSS, GPI, PFKP, GOT1, GSTM2, LDHA, MDH2 and ALDH9A1) were also common to UF, seminal plasma and sperm. In human seminal plasma, glycolytic enzymes may enable sperm to produce ATP (Ronquist et al., 2013).

In conclusion, the present work improves our knowledge of the protein content of avian UF and using proteomics demonstrates for the first time that avian UF contains EV, mainly exosomes. The latter were purified and immunodetection associated with transmission microscopy approaches supported this result. Exosomes may play a key role in the preservation of sperm functions, by participating in long-term sperm storage in chicken. Moreover, the proteins we identified in the UF which are linked to shell formation may constitute a support for sperm survival. The presence of antimicrobial proteins may ensure a bacteria-free environment for sperm as well as sperm acceptance.

\section{Authors' contribution}

CR participated to the conception of the study, coordinated and participated to the experimental procedures and collection of the biological samples, performed experiments, analyzed data and wrote the manuscript. AB actively participated to the analysis of the proteomic data. LC actively participated to the collection of the biological samples, performed experiments, and corrected the manuscript. GH, AG and VL performed the nano LC MS/MS analysis and protein identification. JG participated to the conception of the study and collection of the biological samples. NG conceived the study and participated in its design, coordination and in the collection of biological samples, found the financial support and corrected the manuscript.

\section{Declaration of interest}


The authors declare no conflict of interest.

\section{Funding}

This research was financed by the Conseil Régional du Centre Val de Loire and INRA, the French National Institute for Agricultural Research. Dr. Cindy Riou was supported by the French Association ALLICE. Dr. Luiz Cordeiro was supported by the CNPq, Brazilian National Council of Scientific and Technological Development, on the Science Without Borders fellowship program (grant number 200391/2014-3). The high resolution mass spectrometer was financed (SMHART project $\mathrm{n}^{\circ}$ 3069) by the European Regional Development Fund (ERDF), the Conseil Régional du Centre, the French National Institute for Agricultural Research (INRA) and the French National Institute of Health and Medical Research (Inserm).

\section{Acknowledgments}

We are grateful to the personnel of the Avian experimental unit (UE-PEAT, INRA, Nouzilly, France) for the care of birds. We would like to thank the personnel of the PIC platform (PRC, INRA, Nouzilly, France), MIMA2 platform (MET-GABI, INRA, Jouy-en-Josas, France), and of the laboratory of animal infection expertise (ISP, INRA, Nouzilly) for providing help and technical expertise in microscopy approach. We thank Carmen Alminana for providing the protocole for EV preparation. We thank Sophie Réhault-Godbert and Jean-Pierre Brillard for their helpful discussions during the writing of the manuscript. Lucie Combes-Soia is sincerely thanked for the submission of the dataset to ProteomeXchange via the PRIDE database, and Susan Edrich for correction of the English.

\section{References}

Ahammad, M. U., Miyazato, T., Nishino, C., Tatemoto, H., Okura, N., Okamoto, S., . . Nakada, T. (2013). Effects of Fluid Secreted from the Uterus on Duration of Fertile Egg Production in Hens, and Survivability and Penetrability of Fowl Sperm in vitro. Journal of Poultry Science, 50(1), 74-82. doi:10.2141/jpsa.0120045

Alminana, C., Corbin, E., Tsikis, G., Alcantara-Neto, A. S., Labas, V., Reynaud, K., . . . Mermillod, P. (2017). Oviduct extracellular vesicles protein content and their role during oviduct-embryo cross-talk. Reproduction, 154(3), 153-168. doi:10.1530/REP17-0054

Bakst, M. R. (2011). Physiology and endocrinology symposium: role of the oviduct in maintaining sustained fertility in hens. J Anim Sci, 89(5), 1323-1329. doi:10.2527/jas.2010-3663

Bakst, M. R., \& Akuffo, V. (2009). Morphology of the turkey vagina with and without an egg mass in the uterus. Poult Sci, 88(3), 631-635. doi:10.3382/ps.2007-00527

Bakst, M. R., \& Bauchan, G. (2015). Apical blebs on sperm storage tubule epithelial cell microvilli: their release and interaction with resident sperm in the turkey hen oviduct. Theriogenology, 83(9), 1438-1444. doi:10.1016/j.theriogenology.2015.01.016

Bakst, M. R., Wishart, G. J., \& Brillard, J. P. (1994). Oviductal sperm selection, transport, and storage in poultry. Poultry Science Reviews, 5, 117-143.

Beaumont, C., Brillard, J. P., Millet, N., \& De Reviers, M. (1992). Comparison of various characteristics of duration of fertility in hens. Br Poult Sci, 33(3), 649-661. doi:10.1080/00071669208417503 
Bendtsen, J. D., Jensen, L. J., Blom, N., Von Heijne, G., \& Brunak, S. (2004). Feature-based prediction of non-classical and leaderless protein secretion. Protein Eng Des Sel, 17(4), 349-356. doi:10.1093/protein/gzh037

Birkhead, T. R., \& Moller, A. P. (1993). Sexual Selection and the Temporal Separation of Reproductive Events - Sperm Storage Data from Reptiles, Birds and Mammals. Biological Journal of the Linnean Society, 50(4), 295-311. doi:DOI 10.1111/j.10958312.1993.tb00933.x

Blesbois, E., \& Caffin, J. P. (1992). 'Serum like' albumin of fowl seminal plasma and effects of albumin on fowl spermatozoa stored at 4 degrees C. Br Poult Sci, 33(3), 663-670. doi:10.1080/00071669208417504

Breque, C., Surai, P., \& Brillard, J. P. (2003). Roles of antioxidants on prolonged storage of avian spermatozoa in vivo and in vitro. Mol Reprod Dev, 66(3), 314-323. doi:10.1002/mrd.10347

Brillard, J. P., Galut, O., \& Nys, Y. (1987). Possible causes of subfertility in hens following insemination near the time of oviposition. Br Poult Sci, 28(2), 307-318. doi:10.1080/00071668708416963

Burns, G., Brooks, K., Wildung, M., Navakanitworakul, R., Christenson, L. K., \& Spencer, T. E. (2014). Extracellular vesicles in luminal fluid of the ovine uterus. PLoS One, 9(3), e90913. doi:10.1371/journal.pone.0090913

Camacho, C., Coulouris, G., Avagyan, V., MA, N., Papadopoulos, J., Bealer, K., \& Madden, T. L. (2009). BLAST+: architecture and applications. BMC Bioinformatics, 10(421), 1-9. doi:10.1186/1471-2105-10-421

Colombo, M., Raposo, G., \& Thery, C. (2014). Biogenesis, secretion, and intercellular interactions of exosomes and other extracellular vesicles. Annu Rev Cell Dev Biol, 30(1530-8995 (Electronic)), 255-289. doi:10.1146/annurev-cellbio-101512-122326

Deutsch, E. W., Csordas, A., Sun, Z., Jarnuczak, A., Perez-Riverol, Y., Ternent, T., . . . Vizcaino, J. A. (2017). The ProteomeXchange consortium in 2017: supporting the cultural change in proteomics public data deposition. Nucleic Acids Res, 45(D1), D1100-D1106. doi:10.1093/nar/gkw936

Dismuke, W. M., Klingeborn, M., \& Stamer, W. D. (2016). Mechanism of Fibronectin Binding to Human Trabecular Meshwork Exosomes and Its Modulation by Dexamethasone. PLoS One, 11(10), e0165326. doi:10.1371/journal.pone.0165326

Dun, M. D., Aitken, R. J., \& Nixon, B. (2012). The role of molecular chaperones in spermatogenesis and the post-testicular maturation of mammalian spermatozoa. Hum Reprod Update, 18(4), 420-435. doi:10.1093/humupd/dms009

Foye-Jackson, O. T., Long, J. A., Bakst, M. R., Blomberg, L. A., Akuffo, V. G., Silva, M. V., . . McMurtry, J. P. (2011). Oviductal expression of avidin, avidin-related protein-2, and progesterone receptor in turkey hens in relation to sperm storage: effects of oviduct tissue type, sperm presence, and turkey line. Poult Sci, 90(7), 1539-1547. doi:10.3382/ps.2010-01159

Froman, D. (2003). Deduction of a model for sperm storage in the oviduct of the domestic fowl (Gallus domesticus). Biol Reprod, 69(1), 248-253. doi:10.1095/biolreprod.102.013482

Fujihara, N., \& Koga, O. (1984). Prevention of the Production of Lipid Peroxide in Rooster Spermatozoa. Animal Reproduction Science, 7(4), 385-390. doi:Doi 10.1016/03784320(84)90023-X

Gautron, J., Guyot, N., Brionne, A., \& Réhault-Godbert, S. (2019). CHAPTER 14 Bioactive Minor Egg Components. In Eggs as Functional Foods and Nutraceuticals for Human Health (pp. 259-284): The Royal Society of Chemistry. 
Gautron, J., Hincke, M. T., \& Nys, Y. (1997). Precursor matrix proteins in the uterine fluid change with stages of eggshell formation in hens. Connect Tissue Res, 36(3), 195-210. doi:10.3109/03008209709160220

Gautron, J., Murayama, E., Vignal, A., Morisson, M., McKee, M. D., Rehault, S., . . Hincke, M. T. (2007). Cloning of ovocalyxin-36, a novel chicken eggshell protein related to lipopolysaccharide-binding proteins, bactericidal permeability-increasing proteins, and plunc family proteins. J Biol Chem, 282(8), 5273-5286. doi:10.1074/jbc.M610294200

Gum, E. T., Swanson, R. A., Alano, C., Liu, J., Hong, S., Weinstein, P. R., \& Panter, S. S. (2004). Human serum albumin and its N-terminal tetrapeptide (DAHK) block oxidantinduced neuronal death. Stroke, 35(2), 590-595. doi:10.1161/01.STR.0000110790.05859.DA

Hincke, M. T., Gautron, J., Tsang, C. P., McKee, M. D., \& Nys, Y. (1999). Molecular cloning and ultrastructural localization of the core protein of an eggshell matrix proteoglycan, ovocleidin-116. J Biol Chem, 274(46), 32915-32923. Retrieved from http://www.ncbi.nlm.nih.gov/pubmed/10551857

Hincke, M. T., Nys, Y., Gautron, J., Mann, K., Rodriguez-Navarro, A. B., \& McKee, M. D. (2012). The eggshell: structure, composition and mineralization. Front Biosci (Landmark Ed), 17, 1266-1280. Retrieved from http://www.ncbi.nlm.nih.gov/pubmed/22201802

Hiyama, G., Matsuzaki, M., Mizushima, S., Dohra, H., Ikegami, K., Yoshimura, T., . . . Sasanami, T. (2014). Sperm activation by heat shock protein 70 supports the migration of sperm released from sperm storage tubules in Japanese quail (Coturnix japonica). Reproduction, 147(2), 167-178. doi:10.1530/REP-13-0439

Holm, L., \& Ridderstrale, Y. (1998). Localization of carbonic anhydrase in the sperm-storing regions of the turkey and quail oviduct. Histochem $J, 30(7), 481-488$. Retrieved from http://www.ncbi.nlm.nih.gov/pubmed/10192531

Holm, L., Ridderstrale, Y., \& Knutsson, P. G. (1996). Localisation of carbonic anhydrase in the sperm storing regions of the domestic hen oviduct. Acta Anat (Basel), 156(4), 253260. Retrieved from http://www.ncbi.nlm.nih.gov/pubmed/9078396

Huang, A., Isobe, N., \& Yoshimura, Y. (2017). Changes in localization and density of CD63positive exosome-like substances in the hen oviduct with artificial insemination and their effect on sperm viability. Theriogenology, 101, 135-143. doi:10.1016/j.theriogenology.2017.06.028

Ignotz, G. G., Cho, M. Y., \& Suarez, S. S. (2007). Annexins are candidate oviductal receptors for bovine sperm surface proteins and thus may serve to hold bovine sperm in the oviductal reservoir. Biol Reprod, 77(6), 906-913. doi:10.1095/biolreprod.107.062505

Jalkanen, J., Kotimaki, M., Huhtaniemi, I., \& Poutanen, M. (2006). Novel epididymal protease inhibitors with Kazal or WAP family domain. Biochem Biophys Res Commun, 349(1), 245-254. doi:10.1016/j.bbrc.2006.08.023

Koehler, J. K., Nudelman, E. D., \& Hakomori, S. (1980). A collagen-binding protein on the surface of ejaculated rabbit spermatozoa. J Cell Biol, 86(2), 529-536. Retrieved from http://www.ncbi.nlm.nih.gov/pubmed/6995466

Labas, V., Grasseau, I., Cahier, K., Gargaros, A., Harichaux, G., Teixeira-Gomes, A. P., .. . Blesbois, E. (2015). Qualitative and quantitative peptidomic and proteomic approaches to phenotyping chicken semen. J Proteomics, 112, 313-335. doi:10.1016/j.jprot.2014.07.024

Lee, B., Park, I., Jin, S., Choi, H., Kwon, J. T., Kim, J., . . Cho, C. (2011). Impaired spermatogenesis and fertility in mice carrying a mutation in the Spink2 gene expressed predominantly in testes. $J$ Biol Chem, 286(33), 29108-29117. doi:10.1074/jbc.M111.244905 
Long, E. L., Sonstegard, T. S., Long, J. A., Van Tassell, C. P., \& Zuelke, K. A. (2003). Serial analysis of gene expression in turkey sperm storage tubules in the presence and absence of resident sperm. Biol Reprod, 69(2), 469-474. doi:10.1095/biolreprod.102.015172

Marie, P., Labas, V., Brionne, A., Harichaux, G., Hennequet-Antier, C., Nys, Y., \& Gautron, J. (2015). Quantitative proteomics and bioinformatics analysis provide new insight into protein function during avian eggshell biomineralization. J Proteomics, 113, 178193.

Nakamura, M., Moriya, M., Baba, T., Michikawa, Y., Yamanobe, T., Arai, K., .. . Kobayashi, T. (1993). An endoplasmic reticulum protein, calreticulin, is transported into the acrosome of rat sperm. Exp Cell Res, 205(1), 101-110. doi:10.1006/excr.1993.1063

Ng, Y. H., Rome, S., Jalabert, A., Forterre, A., Singh, H., Hincks, C. L., \& Salamonsen, L. A. (2013). Endometrial Exosomes/Microvesicles in the Uterine Microenvironment: A New Paradigm for Embryo-Endometrial Cross Talk at Implantation. PLoS One, 8(3). doi:ARTN e58502

10.1371/journal.pone.0058502

Nys, Y., Gautron, J., Garcia-Ruiz, J. M., \& Hincke, M. T. (2004). Avian eggshell mineralization: biochemical and functional characterization of matrix proteins. Comptes Rendus Palevol, 3(6-7), 549-562. doi:10.1016/j.crpv.2004.08.002

Park, K. H., Kim, B. J., Kang, J., Nam, T. S., Lim, J. M., Kim, H. T., . . Kim, U. H. (2011). $\mathrm{Ca} 2+$ signaling tools acquired from prostasomes are required for progesterone-induced sperm motility. Sci Signal, 4(173), ra31. doi:10.1126/scisignal.2001595

Perez-Riverol, Y., Csordas, A., Bai, J., Bernal-Llinares, M., Hewapathirana, S., Kundu, D. J., ... Vizcaino, J. A. (2019). The PRIDE database and related tools and resources in 2019: improving support for quantification data. Nucleic Acids Res, 47(D1), D442D450. doi:10.1093/nar/gky1106

Petersen, T. N., Brunak, S., von Heijne, G., \& Nielsen, H. (2011). SignalP 4.0: discriminating signal peptides from transmembrane regions. Nat Methods, 8(10), 785-786. doi:10.1038/nmeth. 1701

Piehl, L. L., Fischman, M. L., Hellman, U., Cisale, H., \& Miranda, P. V. (2013). Boar seminal plasma exosomes: effect on sperm function and protein identification by sequencing. Theriogenology, 79(7), 1071-1082. doi:10.1016/j.theriogenology.2013.01.028

Raymond, A., Ensslin, M. A., \& Shur, B. D. (2009). SED1/MFG-E8: a bi-motif protein that orchestrates diverse cellular interactions. J Cell Biochem, 106(6), 957-966. doi:10.1002/jcb. 22076

Réhault-Godbert, S., Hervé-Grépinet, V., Gautron, J., Cabau, C., Nys, Y., \& Hincke, M. (2011). 9 - Molecules involved in chemical defence of the chicken egg. In Improving the Safety and Quality of Eggs and Egg Products (pp. 183-208): Woodhead Publishing.

Ronquist, K. G., Ek, B., Stavreus-Evers, A., Larsson, A., \& Ronquist, G. (2013). Human prostasomes express glycolytic enzymes with capacity for ATP production. Am J Physiol Endocrinol Metab, 304(6), E576-582. doi:10.1152/ajpendo.00511.2012

Sasanami, T., Matsuzaki, M., Mizushima, S., \& Hiyama, G. (2013). Sperm storage in the female reproductive tract in birds. J Reprod Dev, 59(4), 334-338. Retrieved from http://www.ncbi.nlm.nih.gov/pubmed/23965601

Silphaduang, U., Hincke, M. T., Nys, Y., \& Mine, Y. (2006). Antimicrobial proteins in chicken reproductive system. Biochem Biophys Res Commun, 340(2), 648-655. doi:10.1016/j.bbrc.2005.12.054

Slowinska, M., Bukowska, J., Hejmej, A., Bilinska, B., Kozlowski, K., Jankowski, J., \& Ciereszko, A. (2015). Hepatocyte growth factor activator is a potential target 
proteinase for Kazal-type inhibitor in turkey (Meleagris gallopavo) seminal plasma. Theriogenology, 84(3), 425-436 e423. doi:10.1016/j.theriogenology.2015.03.026

Sullivan, R., Saez, F., Girouard, J., \& Frenette, G. (2005). Role of exosomes in sperm maturation during the transit along the male reproductive tract. Blood Cells Mol Dis, 35(1), 1-10. doi:10.1016/j.bcmd.2005.03.005

Sun, C., Xu, G., \& Yang, N. (2013). Differential label-free quantitative proteomic analysis of avian eggshell matrix and uterine fluid proteins associated with eggshell mechanical property. Proteomics, 13(23-24), 3523-3536. doi:10.1002/pmic.201300286

Talevi, R., \& Gualtieri, R. (2001). Sulfated glycoconjugates are powerful modulators of bovine sperm adhesion and release from the oviductal epithelium in vitro. Biol Reprod, 64(2), 491-498. Retrieved from http://www.ncbi.nlm.nih.gov/pubmed/11159351

Talevi, R., \& Gualtieri, R. (2010). Molecules involved in sperm-oviduct adhesion and release. Theriogenology, 73(6), 796-801. doi:10.1016/j.theriogenology.2009.07.005

Thery, C., Amigorena, S., Raposo, G., \& Clayton, A. (2006). Isolation and characterization of exosomes from cell culture supernatants and biological fluids. Curr Protoc Cell Biol, Chapter 3(1934-2616 (Electronic)), Unit 3 22. doi:10.1002/0471143030.cb0322s30

Valadi, H., Ekstrom, K., Bossios, A., Sjostrand, M., Lee, J. J., \& Lotvall, J. O. (2007). Exosome-mediated transfer of mRNAs and microRNAs is a novel mechanism of genetic exchange between cells. Nat Cell Biol, 9(6), 654-659. doi:10.1038/ncb1596

Wellman-Labadie, O., Lakshminarayanan, R., \& Hincke, M. T. (2008). Antimicrobial properties of avian eggshell-specific C-type lectin-like proteins. FEBS Lett, 582(5), 699-704. doi:10.1016/j.febslet.2008.01.043

Yu, B., \& Huang, Z. (2015). Variations in Antioxidant Genes and Male Infertility. Biomed Res Int, 2015, 513196. doi:10.1155/2015/513196 
822 Table 1. UF proteins potentially linked to the process of shell mineralization clustered in 3 823 groups according to their functions.

824 Table 2. UF proteins linked to antimicrobial activities clustered in 5 groups according to their 825 functions.

826 Figure 1. Schematic representation of the hen's genital tract at ovulation (A) and fluid 827 collection, 10 hours post oviposition (B).

828 Figure 2. Proteomic analysis of avian UF. (A) Distribution of the 913 proteins from the UF in 829 relation to taxonomy. (B) Venn diagram of proteins identified in the present study and studies 830 from Marie et al. (2015) and Sun et al. (2013).

831 Figure 3. Venn diagram of identified proteins in the UF categorized either as not secreted 832 (orange, 437 proteins), or secreted containing a signal peptide (PS, pink, 155 proteins) or not 833 (NCP, yellow, 321 proteins), and EV/exosomal proteins (4643 proteins, UniprotKB, Exocarta 834 and KEGG databases).

835 Figure 4. Analysis of EV from the UF. (A) Purification of the EV containing exosomes 836 (arrowheads) observed by transmission electron microscopy. (B) Distribution of the size of EV. 837 (C) Immunodetection of exosomal (VCP, HSP90A, HSPA8, ANXA2, MDH1, ANXA5, 838 ANXA1, ANXA4, PARK7) and non-exosomal (BPIFB3, OC-17) proteins from UF. Selected proteins observed in UF by mass spectrometry were analyzed using western blot of the UF (lane 840 1), EV-depleted UF (lane 2), and EV (lane 3) using primary antibodies directed against proteins 841 either previously observed in exosomes, or not. Numbers on the left of each blot represent 842 molecular weight $(\mathrm{kDa})$ from a simultaneous protein standard run. All lanes contained $10 \mu \mathrm{g}$ 843 of proteins.

844 Figure 5. Transmission electron microscopy of the uterovaginal junction. (A) Exosomes 845 (arrowheads) $(<100 \mathrm{~nm})$ were observed at surface epithelium of uterovaginal junction. (B) 846 Intracellular MVB containing exosomes $(<100 \mathrm{~nm})$ were observed. (C) Blebs containing 847 microvesicles $(100-1000 \mathrm{~nm})$ were present in the lumen of the SST. The figure is representative 848 of numerous observations. Bl: Bleb; Lu: Lumen; MVB: Multivesicular Bodies.

849 Figure 6. Immunohistochemistry on UVJ and SST. (A) Negative controls for 850 immunohistochemistry performed with mouse (left) and rabbit (right) immunoglobulins instead 851 of the primary antibody. (B) VCP positive signal was observed in UVJ and SST epithelium. 852 (C) PARK7 positive signal was present in UVJ and SST epithelium. (D) ANXA4 positive signal 853 was observed in the apical SST epithelium and the UVJ cilia. The figure is representative of 854 numerous observations. sst: sperm storage tubules; lu: lumen; UVJ ep: pseudostratified 855 epithelium from uterovaginal junction.

856 Figure 7. Pie chart representing molecular functions of the 913 proteins from the avian UF(A) 857 and the 640 proteins referenced in exosome databases (B). MVB: Multivesicular Bodies. 
858 Figure 8. Venn diagram of the 913 proteins identified in UF categorized either as non-exosomal 859 (blue, 589 proteins), or exosomal (green, 640 proteins), compared to proteins identified in 860 seminal plasma (SP, grey, 607 proteins) and spermatozoa (SPZ, yellow, 822 proteins) from 861 roosters. Data provided by Labas et al., (2015).

862 

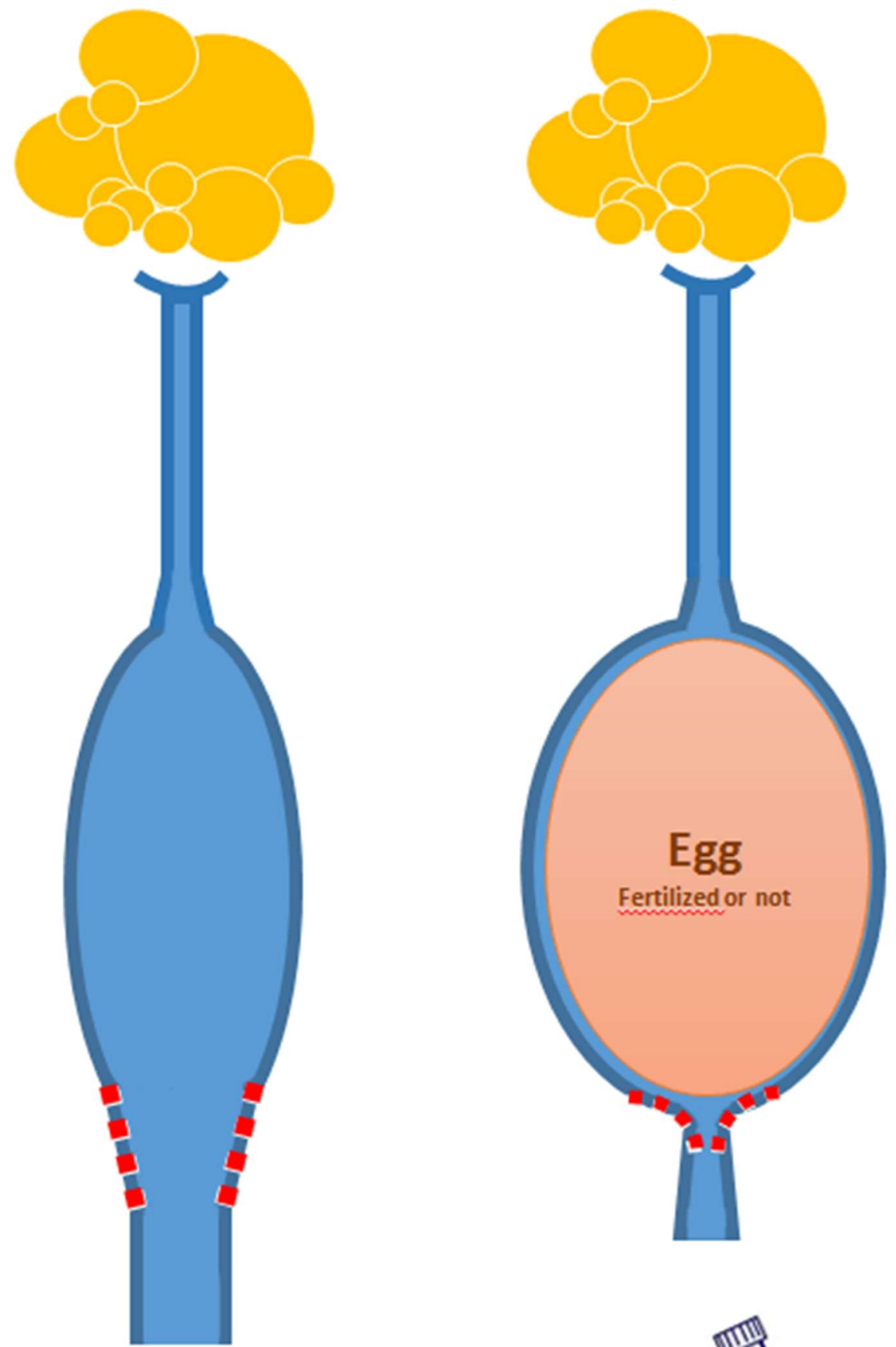
A

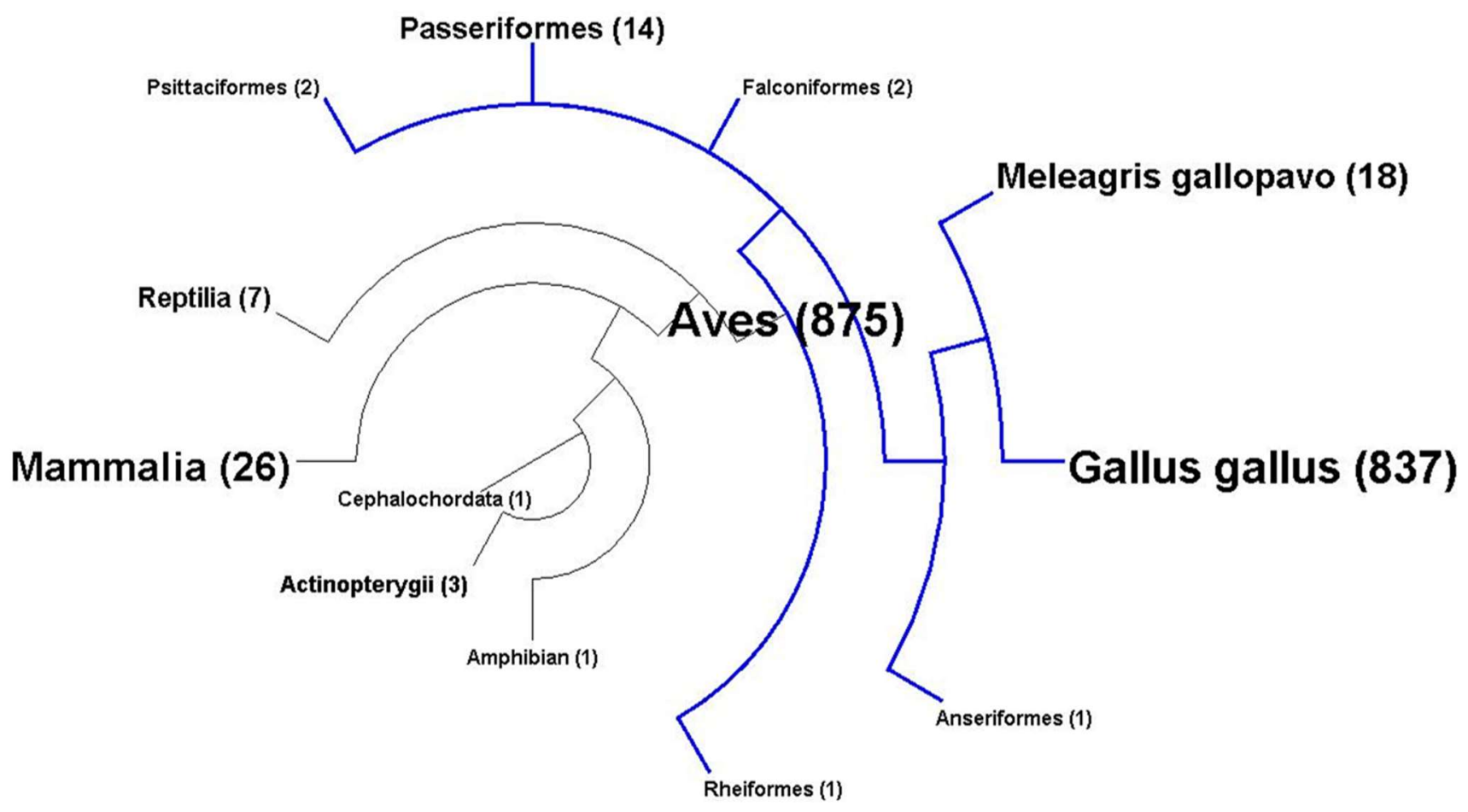

B

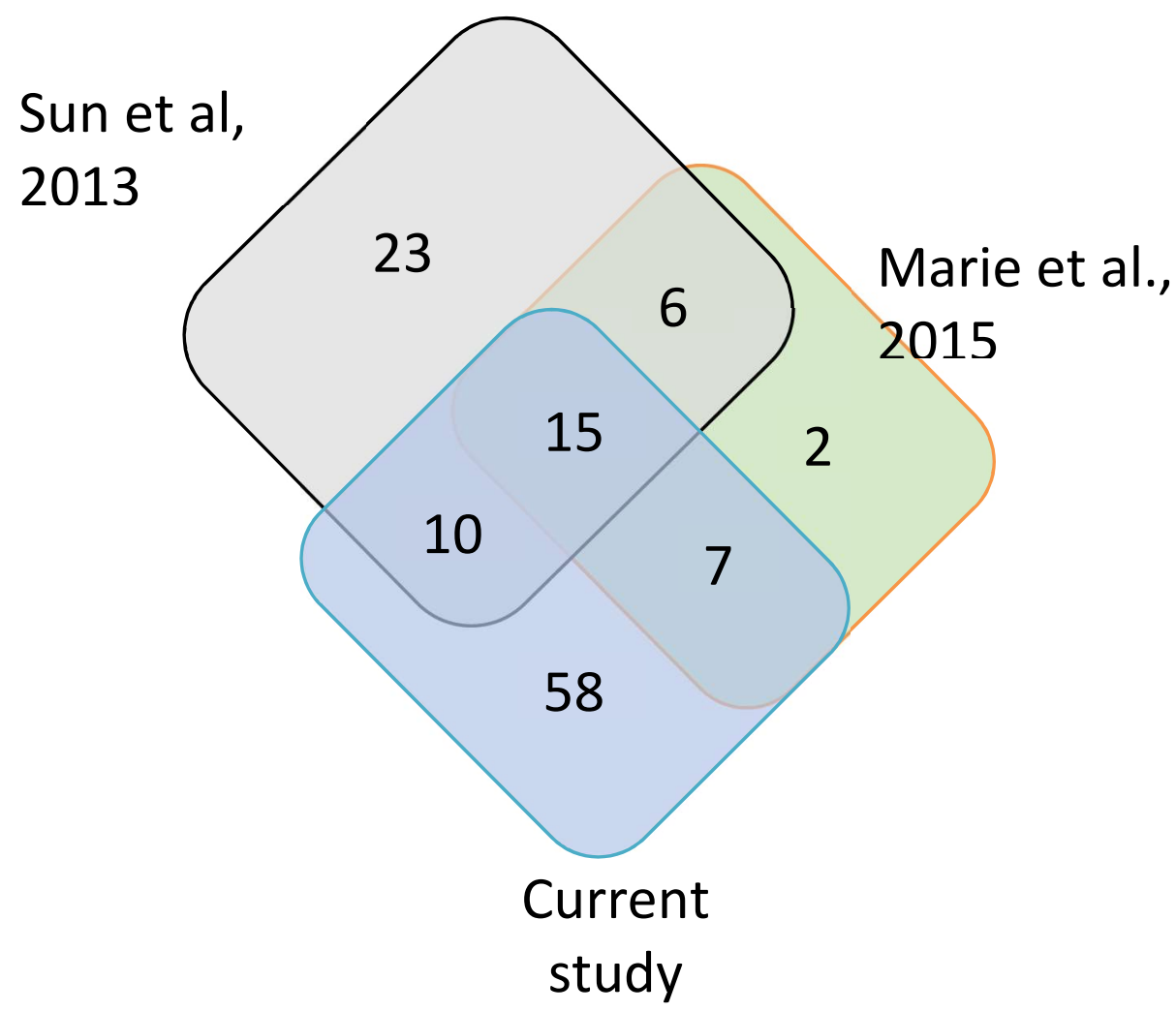

Figure 2 


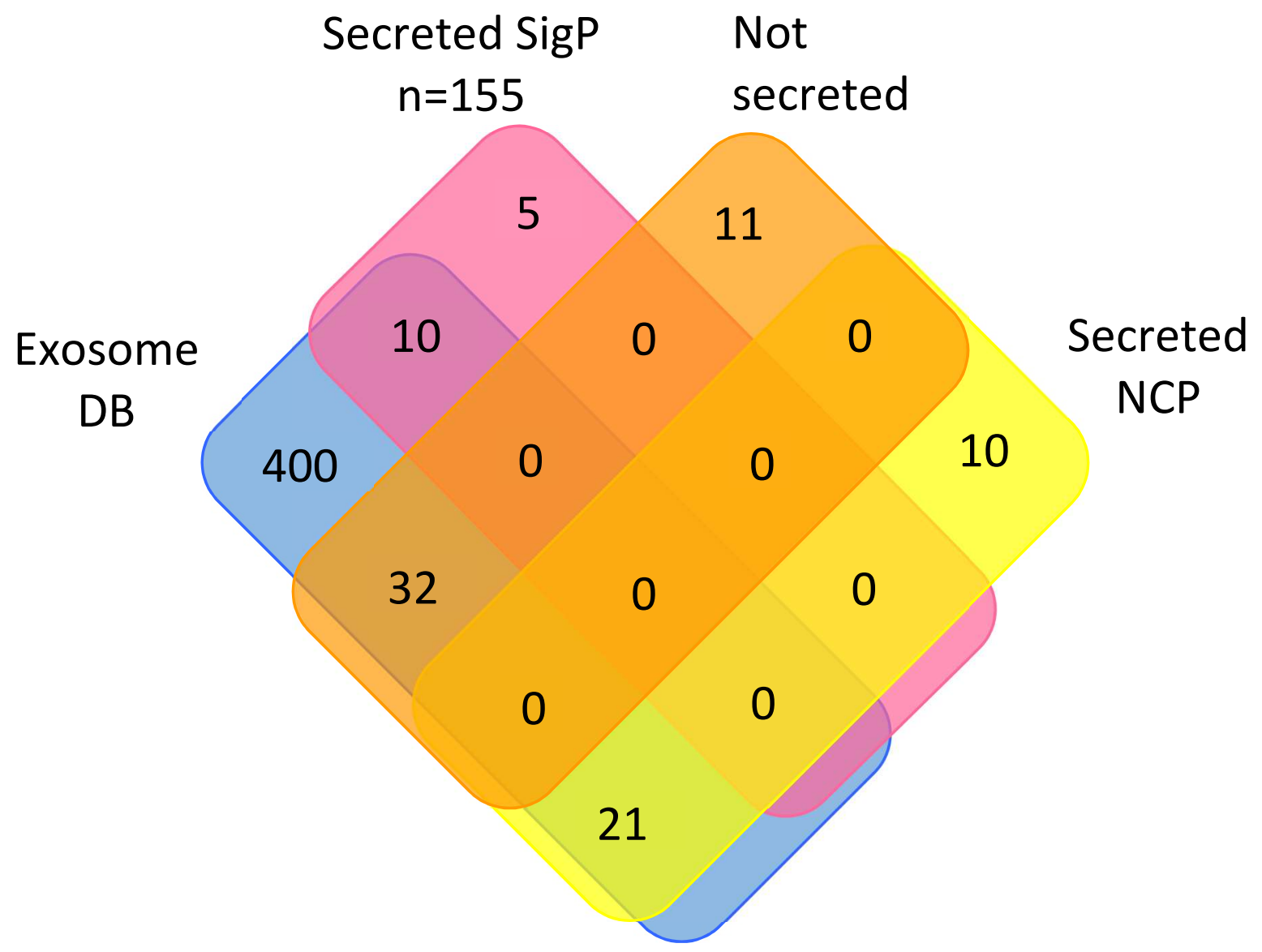



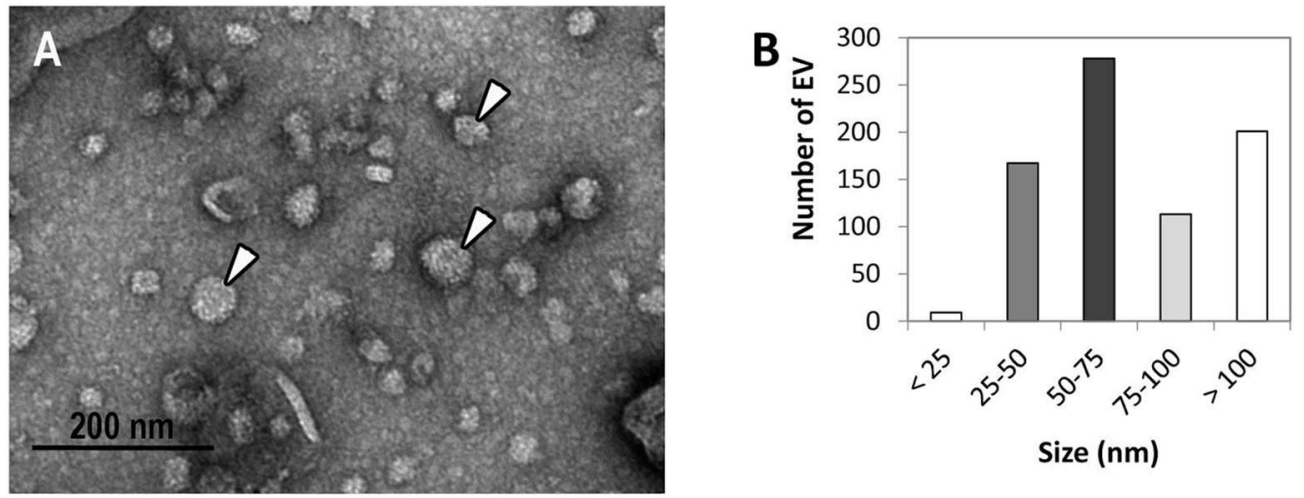

C

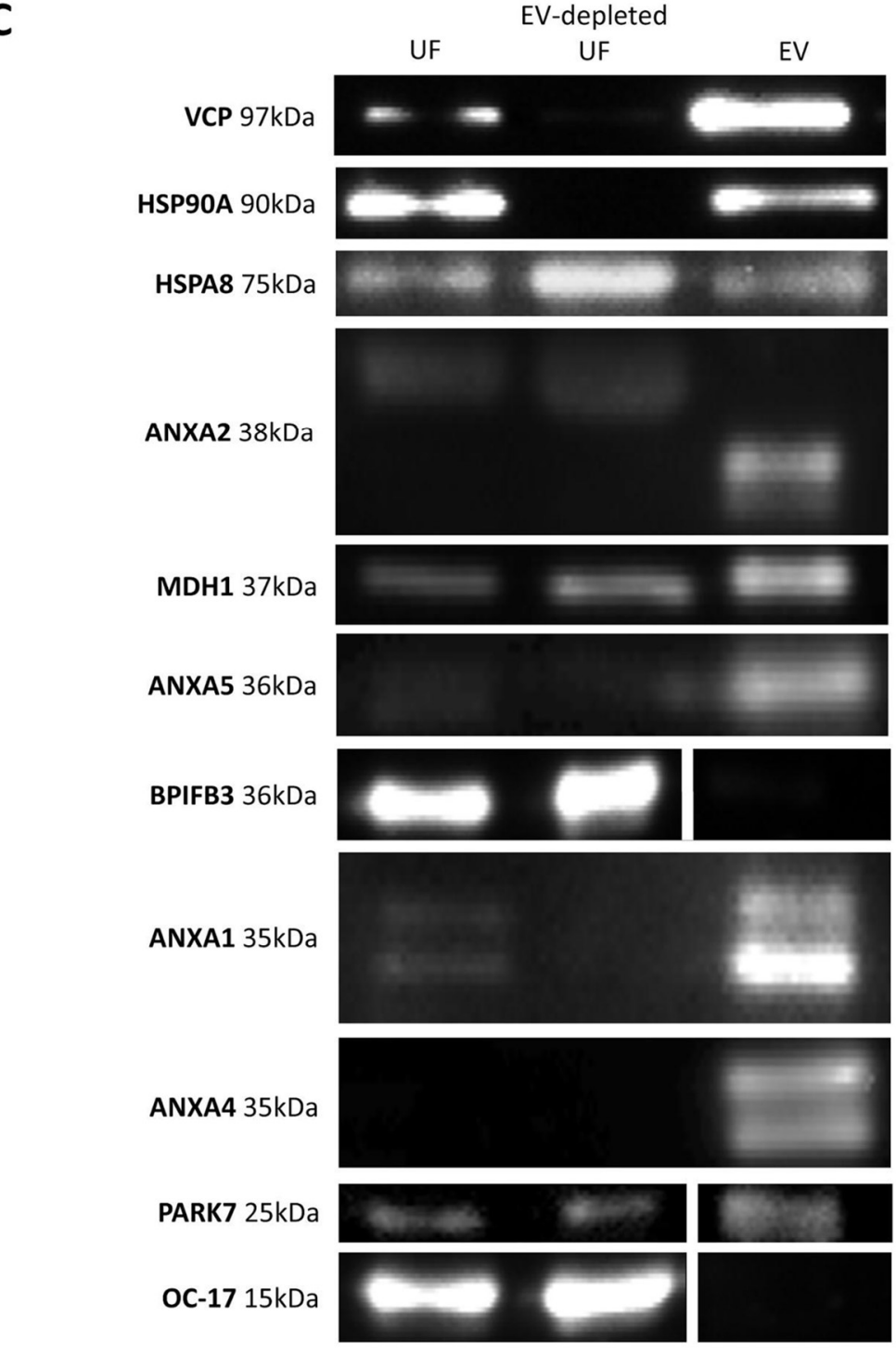

872

873

Figure 4

874 

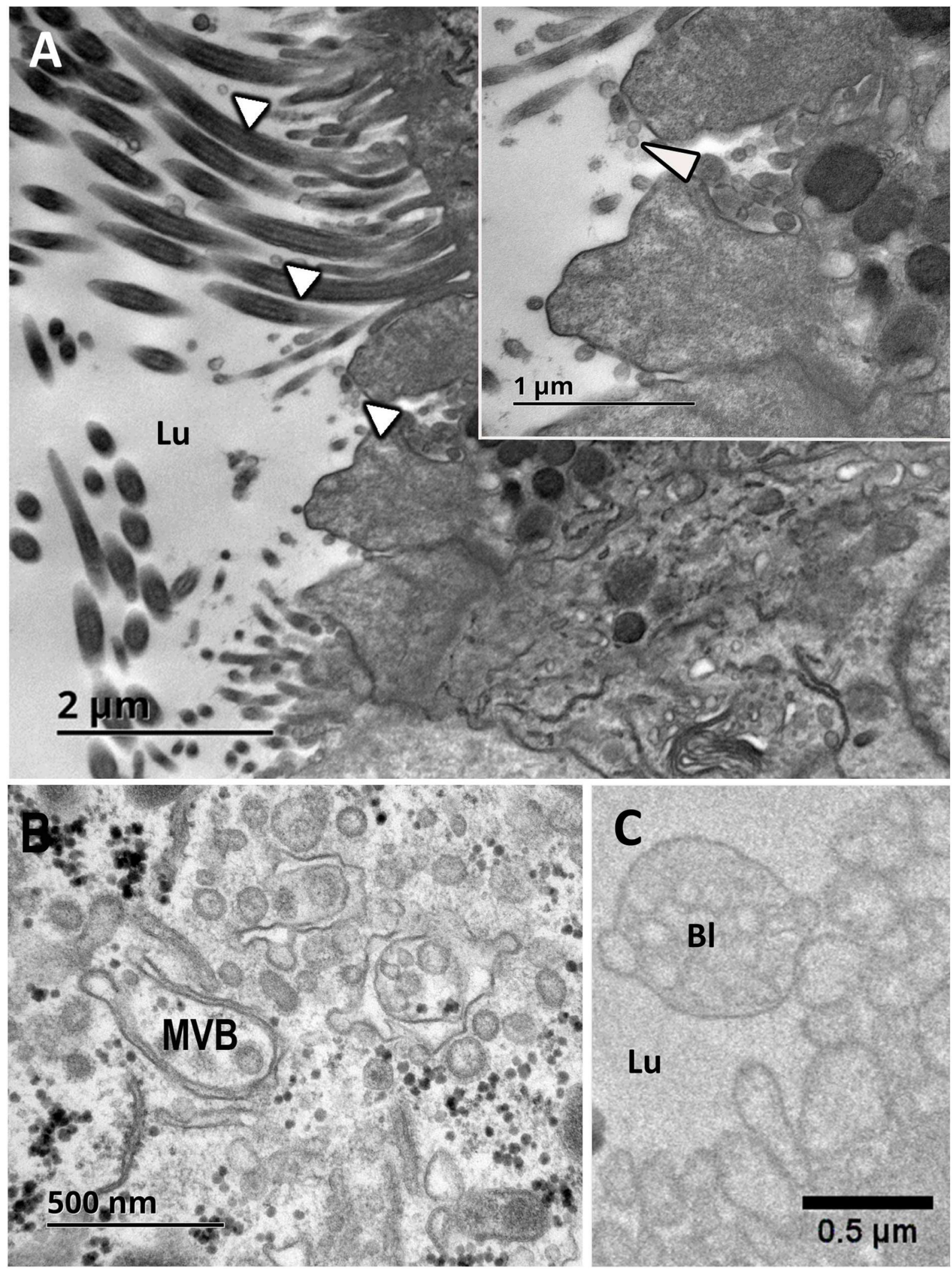

876

Figure5

877 

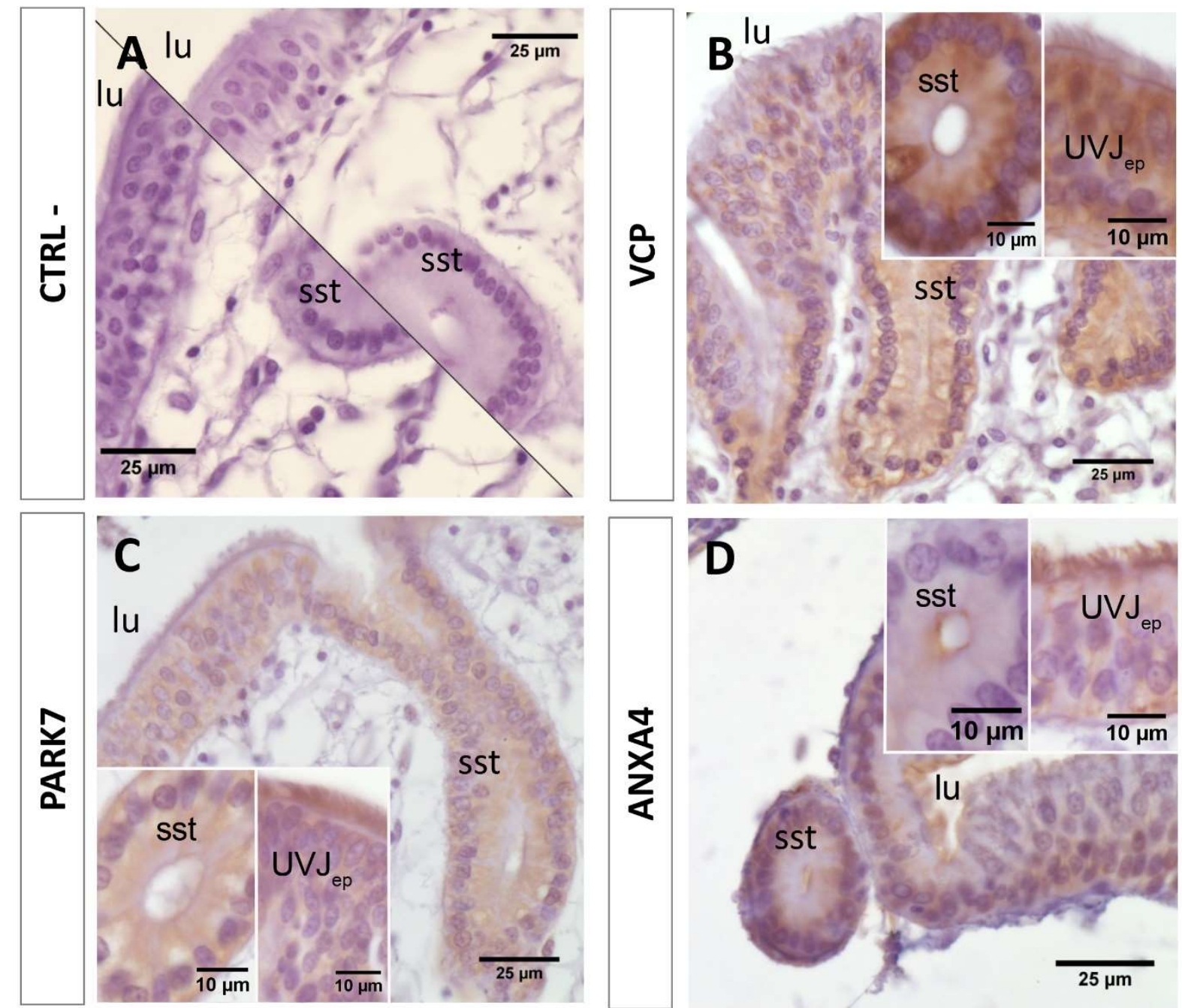

Figure 6 

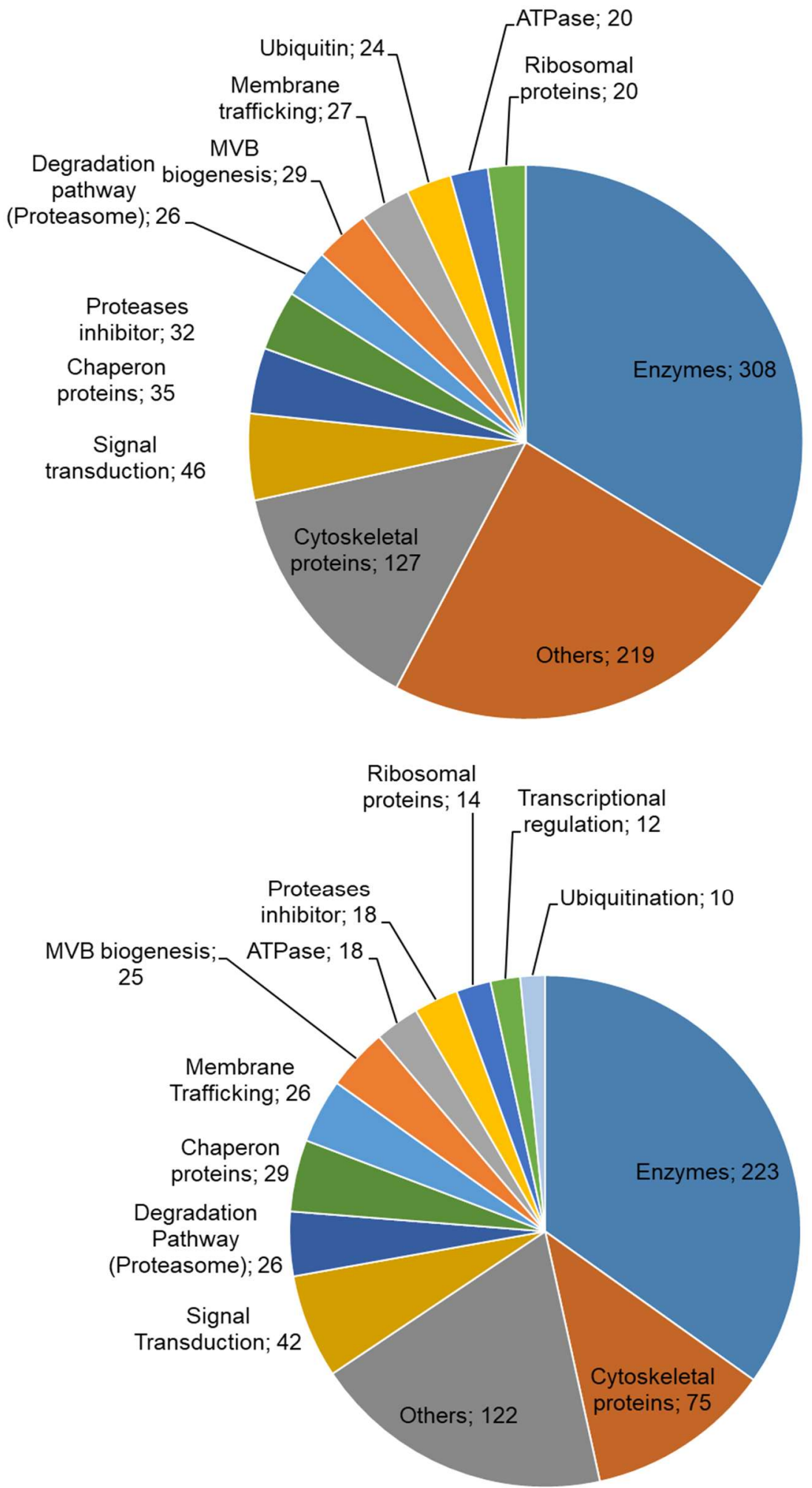


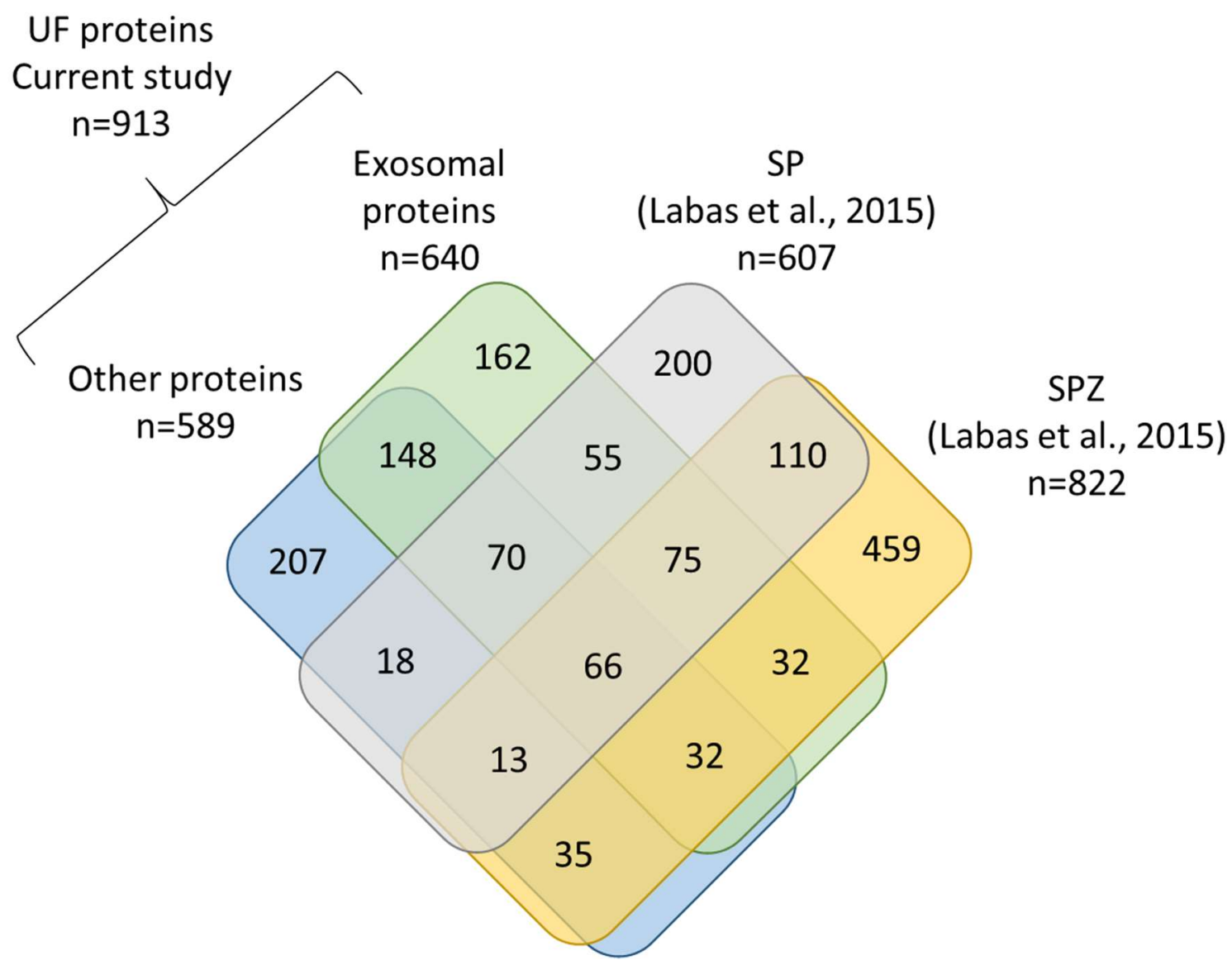

